\title{
NISTIR 88-3822
}

\section{Environment Effects of Oil Spill Combustion}

\author{
D. Evans, G. Mulholland, D. Gross, H. Baum, and K. Saito
}

U.S. DEPARTMENT OF COMMERCE

National Institute of Standards and Technology

(Formerly National Bureau of Standards

National Engineering Laboratory

Center for Fire Research

Gaithersburg, MD 20899

September 1987

Issued September 1988

Sponsored by

Minerals Management Service

Department of the Interior

Reston, VA 22091

$Q C-$
100
U56

$88-3822$

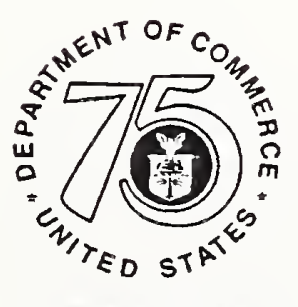





\section{Environment Effects of Oil Spill Combustion}

D. Evans, G. Mulholland, D. Gross, and H. Baum

U.S. DEPARTMENT OF COMMERCE

National Institute of Standards and Technology

(Formerly National Bureau of Standards

National Engineering Laboratory

Center for Fire Research

Gaithersburg, MD 20899

K. Saito

Department of Mechanical Engineering

University of Kentucky

Lexington, KY 40506

September 1987

Issued September 1988

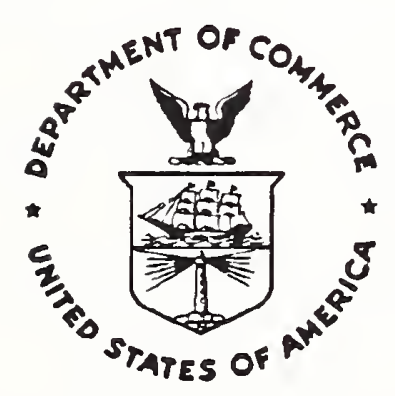

National Bureau of Standards became the National Institute of Standards and Technology on August 23, 1988, when the Omnibus Trade and Competitiveness Act was signed. NIST retains all NBS functions. Its new programs will encourage improved use of technology by U.S. industry.

Sponsored by

Minerals Management Service

Department of the Interior

Reston, VA 22091

\section{U.S. DEPARTMENT OF COMMERCE \\ C. William Verity, Secretary}

NATIONAL INSTITUTE OF STANDARDS

AND TECHNOLOGY

Ernest Ambler, Director 
List of Tables $\ldots \ldots \ldots \ldots \ldots \ldots \ldots \ldots \ldots \ldots \ldots \ldots \ldots \ldots$ iv

List of Figures $\ldots \ldots \ldots \ldots \ldots \ldots \ldots \ldots \ldots \ldots \ldots \ldots \ldots$

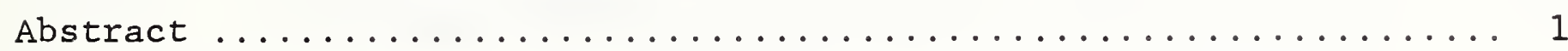

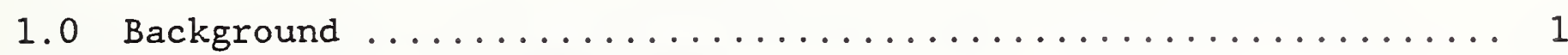

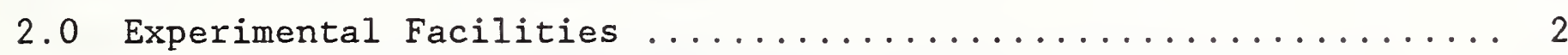

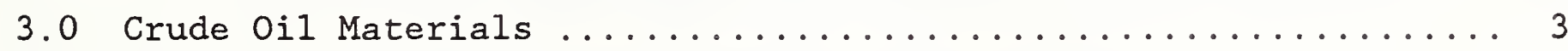

4.0 Burning Characteristics ........................... 3

5.0 Smoke Characteristics $\ldots \ldots \ldots \ldots \ldots \ldots \ldots \ldots \ldots \ldots \ldots \ldots \ldots \ldots \ldots \ldots \ldots$

5.1 Smoke Emission Measurements ..................... 7

5.2 Gas Emission Measurements ...................... 8

5.3 Elemental and Organic Carbon Analysis ............... 8

5.4 Analysis of Polynuclear Aromatic Hydrocarbons ........... 8

5.5 Sample Preparation .......................... 9

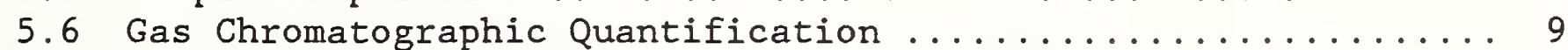

5.7 Results and Discussion ........................... 10

6.0 Plume Dispersal Analysis ......................... 11

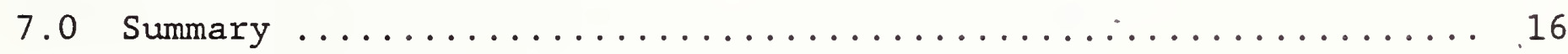

8.0 Acknowledgement $\ldots \ldots \ldots \ldots \ldots \ldots \ldots \ldots \ldots \ldots \ldots \ldots \ldots \ldots \ldots$

9.0 References $\ldots \ldots \ldots \ldots \ldots \ldots \ldots \ldots \ldots \ldots \ldots \ldots \ldots \ldots \ldots \ldots \ldots$ 
Table 1. Properties of Oils (Typical Data) ................ 20

Table 2. Summary of Burning Data in 1.2 dia Pan ............ 21

Table 3. Summary of Smoke Emission Data for $60 \mathrm{CM}$ Diameter Alberta Sweet Crude $0 i 1$ Pool Fires ............... 22

Table 4. Gaseous Emission From Alberta Sweet Crude $0 i 1 \ldots . . . . . .23$

Table 5. Organic/Elemental Analysis of Smoke From Burning of Alberta Sweet Crude Oil ............... 24

Table 6. Mean PAH Concentration for Alberta Sweet Crude Oil Smoke Samples Collected at $100^{\circ} \mathrm{C} \ldots \ldots \ldots \ldots \ldots \ldots . \ldots 25$

Table 7. Mean Pah Concentration for Alberta Sweet Crude Oil Smoke Samples Collected at Ambient Temperature ...... 26

Table 8. Comparison of PAH Content of Alberta Sweet Crude

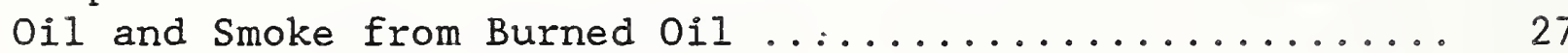


Figure 1. Schematic of Smoke Dilution System ............. 28

Figure 2. Diagrammatic Sketch of Experimental Arrangement ....... 29

Figure 3. Thermocouple Rake for Measurement of Oil-Water

Layer Temperature ...................... 30

Figure 4. Thermal Conductivity of Crude oils ............. 31

Figure 5. Burn Sequence for $10 \mathrm{~mm}$ Thick Layer

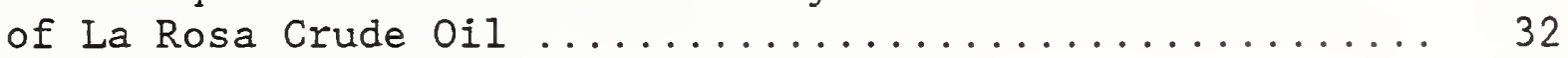

Figure 6. Flame Plume Temperature for Murban Crude

at Different Layer Thickness ................ 33

Figure 7. Energy Release Rate for Murban Crude at

Different Layer Thickness ..................... 34

Figure 8. Recorded Radiation Feedback to Center of

Pan for Murban Crude at Different Layer

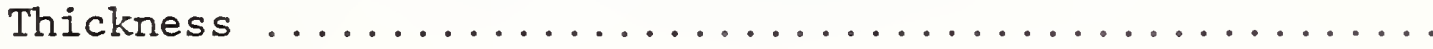

Figure 9. Gas Chromatogram of Typical Blank Sample

with I.S. Indicating Internal Standard

and IMP Indicating an Impurity $\ldots \ldots \ldots \ldots \ldots \ldots \ldots \ldots \ldots \ldots \ldots$

Figure 10. Gas Chromatogram of the First Smoke Sample

Collected at $100^{\circ} \mathrm{C}(\mathrm{H}-2, \mathrm{H})$. The PAHS

Associated with the Peaks are Identified

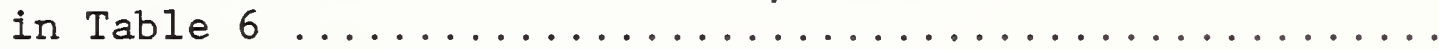

Figure 11. Gas Chromatogram of the Second Smoke Sample

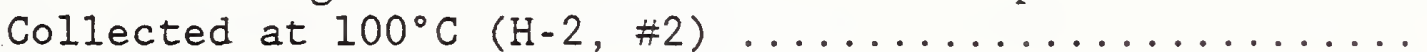

Figure 12. Gas Chromatogram of Smoke Sample Collected

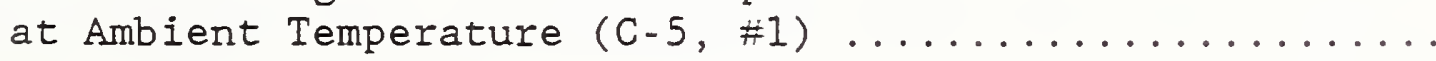

Figure 13. Gas Chromatogram of Second Smoke Sample

Collected at Ambient Temperature (C-5, \#2) ........... 40

Figure 14. Temperature Contours at Front of Wind Blown

Plume Using Transient Enclosure Flow Analogy ...........

Figure 15. Temperature Contours Just Downwind of Fire

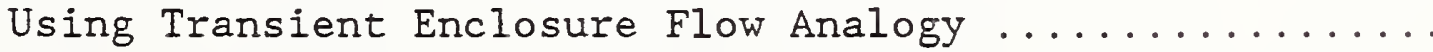

Figure 16. Temperature Contours at Point of Vortex Pair

Formation Using Transient Enclosure Flow Analogy ........ 
List of Figures (continued)

$\underline{\text { Page }}$

Figure 17. Far Downwind Temperature Contours Using Transient Enclosure Flow Analogy ...................... 44 
D. Evans, G Mulholland, D. Gross, H. Baum and K. Saito

\section{ABSTRACT}

Experimentation and analysis have been performed to quantify the combustion of crude oil on water. The burning behavior of three crude oils --Alberta Sweet, La Rosa, and Murban, were studied using $1.2 \mathrm{~m}$ diameter pool burns. In smaller $0.6 \mathrm{~m}$ diameter pool fires using Alberta Sweet, combustion products were collected for extensive chemical analysis. This analysis showed that about $10 \%$ of the crude oil was converted to smoke in the combustion process. The CO concentration was a factor of 25 lower than the primary gaseous product $\mathrm{CO}_{2}$, and the emission of $\mathrm{NO}$ and $\mathrm{NO}_{x}$ were less than one thousandth the concentration of $\mathrm{CO}_{2}$. The $\mathrm{PAH}$ content of the smoke was enriched in the larger molecular weight species in comparison with the original fuel. A methodology was developed with which the down wind dispersal of smoke generated by one or more oil spill fires in close proximity may be predicted. Initial results that demonstrate the capability of the analysis are presented.

\subsection{BACKGROUND}

In 1985, the Center for Fire Research (CFR) at the U.S. National Bureau of Standards (NBS) began studies of oil spill combustion under support from the Minerals Management Service (MMS) of the U.S. Department of the Interior. This work seeks to quantify the processes involved in oil spill combustion on open waters and in water filled channels formed in broken ice including measurements of smoke production and prediction of smoke dispersal. Added support from the U.S. Coast Guard and Environment Canada has allowed the study to be broadened in scope and increased in detail.

The long range goal of the research program is to provide measurements and means to make quantitative predictions of (a) the fraction of oil in a spill that can be consumed by an in-situ combustion process, (b) the characteristics of the residual oil, and (c) the characteristics of the combustion product flow from the burning oil. It is hoped that this information may be cast into a form that is usable by local officials and oil spill response professionals as part of the decision making process in the event of an oil spill.

Last year's study included results from experiments to quantify the burning of $0.60 \mathrm{~m}$ diameter oil pool fires. Measurements of burning rate, thermal radiation emission, smoke production and the chemical composition of both the oil and the burn residue were reported [1]. Calculations were performed to estimate the surface wind velocities that could be generated by multiple fires distributed over a large area as might be expected during the burning of an oil pool confined by broken ice in the arctic. This year's effort is the first in a two year program to quantify (a) the thermal properties and burning characteristics of the crude oil, (b) the physical and chemical properties of the smoke generated in the combustion process, and (c) the expected dispersal of the soot through the atmosphere and deposition down wind of the oil fires. 
This report summarizes results from these three main research thrusts all of which are at the mid-point of the two year effort.

\subsection{EXPERIMENTAL FACILITIES}

Crude oil burn tests were conducted in the CFR large-scale test building using both the large and small calorimeter hoods. The small hood facility could accommodate oil pool fires up to $0.6 \mathrm{~m}$ in diameter. This hood was used to collect all smoke and gas samples for quantitative analysis. Details of this experimental gas and soot sampling installation were reported previously [1]. A new controlled dilution probe, shown in Figure 1, was added to the exhaust stack of the small calorimeter hood for the present studies. This probe is used to cool and dilute the gas sampled from the stack by adding a mass flow of chilled air approximately twice the mass flow of the combustion products sampled. With the addition of this probe to the existing system two sampling conditions for the soot could be examined. The previous system maintained the gas sample at the nominal $100{ }^{\circ} \mathrm{C}$ from the stack to the filters where soot samples were deposited. The new system cools and dilutes the sample such that at the filters the temperature is within $2{ }^{\circ} \mathrm{C}$ of ambient temperature.

For larger test burns, a steel pan measuring $1.20 \mathrm{~m}$ in diameter and $0.30 \mathrm{~m}$ in height was installed under the large calorimeter hood, as shown in Figure 2. The pan was elevated $0.6 \mathrm{~m}$ above the platform floor by means of blocks to allow for the introduction of instrumentation and for supply and drainage of water through the bottom of the pan. A predetermined quantity of oil was floated on the water surface the level of which could be controlled to maintain a burning surface $10 \mathrm{~mm}$ to $12 \mathrm{~mm}$ below the pan rim. Perforated steel plates were arranged to form an artificial "floor" at the level of the pan rim. This was intended to limit, but not to completely exclude, air supply from below the pan rim, and also to allow for liquid spillover during test periods where energetic water boiling was expected to occur based on results of previous smaller scale burns [1]. An annular trough containing a layer of moist sand was located around the pan below the perforated plates to contain any spillover or splattered droplets of burning oil. Sorbent pads of oleophilic polypropylene fiber were used to adsorb the oil remaining on the water surface after each test in order to determine the weight of the residue.

Instrumentation was provided for the measurement of flame temperature; oil and water temperature; energy release rate; radiation feedback from the flames to the liquid surface; and radiation from the flames to the surrounding. Placement of this instrumentation is shown in Figure 2. All thermocouples were of the metallic-sheathed, mineral-insulated type. Two specially-designed thermocouple rakes were commercially fabricated and were mounted to provide temperature measurement along two vertical axes which included the entire oil layer depth plus positions in the fuel-rich air above the oil and in the water. As shown in Figure 3, each thermocouple rake consisted of 13 thermocouples the top seven of which were spaced at $1.5 \mathrm{~mm}$ separation. At the lower positions that extended to $76.2 \mathrm{~mm}$ below the top thermocouple, spacing was gradually increased to $3.1 \mathrm{~mm}, 6.3 \mathrm{~mm}, 12.7 \mathrm{~mm}$, and $25.4 \mathrm{~mm}$. The in-pool radiometers were commercially fabricated instruments of the Schmidt-Boelter type, provided with Irtran windows and nitrogen gas purging as well as water 
cooling. They were positioned approximately $25 \mathrm{~mm}$ above the oil surface facing up at the center, at a quarter-point, and near the rim of the pan.

The energy release rate of the fires burned under this hood are determined using the oxygen consumption calorimeter technique. The energy release rate is calculated from measured decreases in oxygen concentration in the total flow of gases through the stack [2].

\subsection{CRUDE OIL MATERIALS}

The burning characteristics of three types of crude oils were investigated in the large calorimeter - - Alberta Sweet, La Rosa and Murban. These oils were obtained from supplies at the EPA-OHMSETT facility in New Jersey. According to available oil property information [3], reproduced in Table 1, these oils differ in composition, notably in the percent of the heavier wax plus asphaltene fractions, with Alberta Sweet crude being the lowest and La Rosa crude being the highest.

Important thermal characteristics of the crude oils used in this study are being measured. The thermal conductivity of each oil was measured using the transient hot-wire method [4]. In this method the thermal conductivity of the liquid is determined by comparing the measured time dependent temperature change of a wire submerged in the liquid reservoir at known initial temperature with the known analytic solution. The measured results for the three oils over the temperature range $0{ }^{\circ} \mathrm{C}$ to $50{ }^{\circ} \mathrm{C}$ are shown in Figure 4.

\subsection{BURNING CHARACTERISTICS}

The burning characteristics of the three crude oils were measured in burns under the large calorimeter hood. The use of a $1.2 \mathrm{~m}$ diameter pan permitted controlled burning experiments to be conducted under conditions representative of the radiation-dominated, turbulent flow regime of larger pool fires. Each oil was studied at four initial layer thicknesses - $2 \mathrm{~mm}, 5 \mathrm{~mm}, 10 \mathrm{~mm}$, and $25 \mathrm{~mm}$. In each test a pre-weighed sample of oil, corresponding to the desired oil layer thickness, was floated on the water surface. The oil level control device was operated in most tests to maintain the oil surface nominally $12 \mathrm{~mm}$ below the top of the pan rim. At this depth, the two top thermocouples on the rakes were above the oil surface at the start of each test. As soon as the surface was calm and stabilized and all instrumentation was in operating condition (usually within 2 minutes), an ignition flame was applied to the oil surface. All temperatures, radiation levels, heat release rate and exhaust gas measurements were scanned automatically at 5 second intervals and recorded on magnetic tape. After burning ceased, a pre-weighed sorbent pad was placed on the surface to adsorb the residual oil and then the oil soaked pad was reweighed. No attempt was made to capture oil which had splattered over the pan rim or to account for water picked up by the sorbent pad. Oil which remained on the radiometers, thermocouples, and pan surfaces was removed with solvent-moistened napkins, prior to the next test. Photographs showing the typical sequence in a burn are reproduced in Figure 5 . 
To date, 12 tests have been completed. Although the data have not been completely analyzed and evaluated, a summary of selected data is given in Table 2. Principal emphasis in this report will be on discussion of temperatures measured in the flame-plume temperature, energy release rate, and radiation feedback to the oil surface.

For a given crude oil, the maximum recorded flame-plume temperature increased slightly with oil layer thickness. As shown in Figure 6 for the Murban crude, the flame temperature did not reach a steady state condition for oil layer thicknesses of $2 \mathrm{~mm}$ and $5 \mathrm{~mm}$, but approached a steady-state value (before reaching a peak) for the larger thicknesses. The peak temperature corresponding to the vigorous burning period prior to the end of burning was approximately $100{ }^{\circ} \mathrm{C}$ to $150^{\circ} \mathrm{C}$ above the "steady-state" temperature.

The maximum recorded energy release rate also increased with oil layer thickness, but then decreased for the $25 \mathrm{~mm}$ layer. The energy release rate for the Murban crude exhibited an approach to steady-state for the $10 \mathrm{~mm}$ and $25 \mathrm{~mm}$ layer thicknesses prior to reaching a peak value during the vigorous burning period (see Figure 7). The quasi-steady-state energy release rate for the Murban crude was approximately $0.95 \mathrm{MW}\left(840 \mathrm{~kW} / \mathrm{m}^{2}\right)$, actually decreasing noticeably prior to the rapid increase in burning corresponding to a peak level of $2.1 \mathrm{MW}\left(1860 \mathrm{~kW} / \mathrm{m}^{2}\right)$ prior to burnout. The decrease in energy release rate during the steady burning phase (100 to 500) seconds appears to be associated with the changing composition of the crude oil towards the heavier fractions and the concurrent decreased combustion efficiency leading to the apparent generation of more smoke. The corresponding values of steady-state and peak energy release rates for the Alberta Sweet crude were 1.15 MW $\left(1000 \mathrm{~kW} / \mathrm{m}^{2}\right)$ and $2.7 \mathrm{MW}\left(2400 \mathrm{~kW} / \mathrm{m}^{2}\right)$. These values are significantly greater than the area specific energy release rate for Murban crude measured in the $0.6 \mathrm{~m}$ diameter pan $\left(720 \mathrm{~kW} / \mathrm{m}^{2}\right)$. The peak energy release rate for the La Rosa crude was approximately $50 \%$ greater than for the Murban crude.

There was a similar increase in the recorded peak levels of radiant heat feedback to the Murban crude oil surface as a function of oil layer thickness (see Figure 8). However, for the Alberta Sweet and La Rosa crudes, the peak levels of feedback radiation at the center appeared to be lower for the $25 \mathrm{~mm}$ layer than for the $10 \mathrm{~mm}$ layer. Also, the recorded level of feedback radiation did not follow the same temporal pattern of the peaks of the flame temperature and the energy release rate, particularly for the $10 \mathrm{~mm}$ and $25 \mathrm{~mm}$ layer

depths. Several problems with the present radiation measurement system must be overcome to obtain more reliable data. One problem is with the splattering of oil from the pool up onto the radiometers during the vigorous burning period near the end of the test. The other is the nitrogen purging of the radiometers interfering with the normal burning. Intense burning due to fire whirls induced by the nitrogen flow immediately above the radiometers may significantly influence the readings. 
The following observations were noted during this series of tests:

\section{Ignition}

With the Alberta Sweet crude oil, ignition was immediate with active and rapid flaming involving the entire oil layer. With the La Rosa crude, there was a delay of approximately 60 to 90 seconds before the flaming spread to involve the entire surface. The response of the Murban crude was intermediate.

\section{Fire whirls}

Local intense burning, usually with strong vortex motion, was observed in the vicinity of the gas-purged radiometers. This appeared to be the result of the air-aspirating effect of the nitrogen jet used to minimize oil condensation on the radiometer window. This may be noted in the photographic sequence of the $10 \mathrm{~mm}$ La Rosa burn test shown in Figure 5 . Although this activity was very localized and did not appear to affect the overall measurements of external radiation, some in-pool radiation feedback measurements may be affected. Knowledge of this effect may be of interest where methods for increasing local rates of burning are being considered.

\section{Oil splatter.}

During the vigorous burning period, boiling water and oil droplets splattered up and out of the pan. The La Rosa and the Murban crudes caused extensive splattering, with flaming droplets from the former approaching $1 \mathrm{~m}$ in height. The splattering occurred at the end of the test when the remaining thin layer of oil contained a greater percentage of higher boiling point fractions. The increased surface temperature and thin oil thickness caused boiling in the water sublayer.

4. Smoke

The quantity of smoke observed within the flame mass appeared to be greater as the oil layer thickness was increased and smoke appeared to be generated at a greater rate and closer to the oil surface late in the test. The La Rosa and Murban had noticeably more smoke than Alberta Sweet.

5. Boilover

With the Murban and La Rosa crudes at an oil layer thickness of $25 \mathrm{~mm}$, boilover occurred at the end the test. In the test with $25 \mathrm{~mm}$ initial layer depth of La Rosa, the boilover was relatively intense and considerable oil spilled or splattered out over the rim of the pan. The Alberta Sweet crude exhibited only a minor tendency to boilover.

\section{Residue}

The oil residue remaining following burnout varied with the type of oil and the layer thickness. With one exception, more oil remained from the thickest $(25 \mathrm{~mm})$ layer of each oil and slightly more residue remained with the La Rosa crude than with the other oils. The measured residue 
for all tests ranged from $0.6 \mathrm{~kg}$ to $1.2 \mathrm{~kg}$ corresponding to a layer depth of approximately $0.6 \mathrm{~mm}$ to $1.2 \mathrm{~mm}$.

The effectiveness of combustion as an oil spill mitigation tool depends critically upon the feedback of radiation from the flames to the burning oil surface. This project is attempting to emphasize this measurement, particularly since prior investigations reported in the literature $[5,6]$ have experienced experimental difficulties and analytical models have never been fully validated. This study has not been completely immune to similar experimental problems, but significant progress is being made. Initial indications are that radiation feedback to the surface may range from less than 2 percent to more than 5 percent of the total energy release rate depending upon the type of oil and its layer thickness. Based on initial estimates of the temperature gradients at the oil surface $\left(22^{\circ} \mathrm{C} / \mathrm{mm}\right.$ to $\left.50^{\circ} \mathrm{C} / \mathrm{mm}\right)$, and the measured thermal conductivity of the crudes $(0.12 \mathrm{~W} / \mathrm{mK}$ to $0.13 \mathrm{~W} / \mathrm{mK}$ ), the rate of heat conduction into the oil is approximately $2 \mathrm{~kW} / \mathrm{m}^{2}$ to $6 \mathrm{~kW} / \mathrm{m}^{2}$ or less than 20 percent of the radiant energy approaching the surface in these tests. A better estimation will be available with additional tests, improved instrumentation, completion of energy balances, and comparison with a flame radiation model which accounts for radiant energy blockage by the cool fuel vapor-rich zone above the oil surface [7]. Examination of the effects of water temperature, oil spill weathering, and wind on the combustion process will require additional experimentation and calculations.

\subsection{SMOKE CHARACTERISTICS}

The focus of this part of the project is the chemical characterization of the smoke produced by burning crude oil. The measurements include the organic versus elemental carbon in the smoke, the quantity of selected polynuclear aromatic ( $\mathrm{PAH}$ ) compounds in the smoke, and the amount of $\mathrm{CO}_{2}, \mathrm{CO}$, NO, and $\mathrm{NO}_{\mathrm{x}}$ emitted. Much of the analysis effort was concentrated on the PAH analysis. These materials are of environmental concern, because some have been reported to be carcinogenic to animals [8]. The results of the PAH analysis are compared with the PAH component of the fuel itself.

In all tests in this series, Alberta Sweet crude oil was burned in a $0.6 \mathrm{~m}$ diameter pool. Approximately 9 liters of crude oil were burned in each test, which corresponded to a fuel depth of about $30 \mathrm{~mm}$. The sample burning time was found to be about fifteen minutes. Smoke samples were collected on filters heated to match the stack temperature, about $100^{\circ} \mathrm{C}$, using a heated transfer line described in last year's report [1]. The first smoke sample was collected from the time of visually steady burning, typically one minute into the burn, for about six minutes. The collection of a second sample began immediately thereafter and lasted for about another six minutes. Smoke samples were also diluted before collection with air cooled to about $10^{\circ} \mathrm{C}$ to simulate the cooling that would naturally occur in a rising smoke plume. In this case, both filter samples were collected in parallel over about thirteen minutes of the burn. The filter collections in all the tests were completed before the rapid burning at the end of the test. 


\subsection{Smoke Emission Measurements}

The results of the smoke emission measurements are contained in Table 3 . The smoke yield, $\epsilon$, which is defined as the mass of smoke aerosol generated per mass of fuel consumed, is found to have a value of about 0.10. This is similar to the value found in previous test with PRUDHOE BAY crude oil [1]. the value of $\epsilon$ increases in going from sample 1 to sample 2 indicating that the smoke emission increases as the fuel presumably distills leaving the sootier component for the later stage of burning.

One important parameter in regard to visibility effects of the smoke is the specific extinction coefficient relative to the fuel, $\mathrm{K}_{f}$.

$$
\mathrm{K}_{f}=\mathrm{K} /\left(\dot{\mathrm{m}}_{\mathrm{f}} / \dot{\mathrm{V}}\right)
$$

where $\mathrm{K}$ is the extinction coefficient per meter, $\dot{\mathrm{m}}_{\mathrm{f}}$ is the fuel mass loss rate, and $\dot{V}$ is the volumetric flow rate through the duct. As a heuristic example, a $\mathrm{K}_{\mathrm{f}}$ value of $1 \mathrm{~m}^{2} / \mathrm{g}$ means that if the smoke produced by one gram of material were collected over a $1 \mathrm{~m}^{2}$ area, the light incident on this area would be blocked by the smoke $\left(I / I_{0}=e^{-1}\right)$. The value of $K_{f}$ increases from about 0.7 to $1.1 \mathrm{~m}^{2} / \mathrm{g}$ for the second collection period for both $\mathrm{H}-\mathrm{I}$ and $\mathrm{H}-4$ indicating again that the fire becomes sootier as the burning proceeds. The average value of $\mathrm{K}_{f}, 0.87 \mathrm{~m}^{2} / \mathrm{g}$, is close to the value obtained with Prudhoe Bay crude oil, $0.96 \mathrm{~m}^{2} / \mathrm{g}$.

A second optical property of interest is the extinction coefficient per mass concentration of the smoke, $\mathrm{K}_{\mathrm{s}}$, defined by

$$
\mathrm{K}_{\mathrm{s}}=\mathrm{K} / \mathrm{m}_{\mathrm{s}}
$$

where $m_{s}$ is the mass concentration of smoke. The quantity $\mathrm{K}_{\mathrm{s}}$ is an intrinsic property of the smoke depending on (a) the optical properties of the smoke, (b) the size distribution of the smoke, and (c) the wavelength of light. The average value of $9.4 \mathrm{~m}^{2} / \mathrm{g}$ obtained from the first two tests is in good agreement with the value obtained for PRUDHOE BAY crude oil, $9.1 \mathrm{~m}^{2} / \mathrm{g}$.

The smoke collected in tests $\mathrm{C}-5$ and $\mathrm{C}-7$ was first diluted and thus cooled by the probe illustrated in Figure 1. The mass flow of ice cooled dilution air is approximately twice the mass flow of the air sampled from the stack. The manifold temperature just prior to the filter is observed to be within two ${ }^{\circ} \mathrm{C}$ of the ambient temperature. The value of $\epsilon$ obtained under these conditions is $15 \%$ to $20 \%$ less than the value obtained for the heated, undiluted sample. Normally, one would expect an increase in $\epsilon$ with dilution by cool air resulting from the condensation of organic vapors. The PAH analysis discussed below clearly shows that the higher vapor pressure PAH's are greatly enriched in the diluted sample compared to the high temperature sample. The observed decrease in these tests may be the result of smoke deposition by thermophoresis in the entrance portion of the diluter and by turbulent flow in the mixing region of the diluter. 
The emission of $\mathrm{CO}, \mathrm{CO}_{2}$, NO, and $\mathrm{NO}_{\mathrm{x}}$ was monitored during selected tests. The concentrations of $\mathrm{CO}$ and $\mathrm{CO}_{2}$ were measured by standard gas analysis instrumentation based on nondispersive infrared spectroscopy. The smoke aerosol was filtered and the moisture condensed out with a dry ice trap before the sampled gas entered the $\mathrm{CO}$ and $\mathrm{CO}_{2}$ analyzers. The analysis of the nitrogen oxides is based on the reaction of ozone with the oxides and detection of the resulting chemiluminescence with a photocell. The $\mathrm{CO}_{2}$ accounts for over 958 of the gaseous products measured as indicated in Table 4. The other principal product of combustion, $\mathrm{H}_{2} \mathrm{O}$, was not measured. The volume fraction of $\mathrm{CO}$, NO, and $\mathrm{NO}_{\mathrm{x}}$ relative to $\mathrm{CO}_{2}$ were found to be about $0.038,1.5 \times 10^{-4}$, and $4 \times 10^{-4}$, respectively. The concentrations of NO and $\mathrm{NO}_{\mathrm{x}}$ were just above the detection threshold.

\subsection{Elemental and Organic Carbon Analysis}

Smoke aerosol produced by flaming combustion is composed of a graphitic or so called elemental carbon fraction and an organic carbon fraction. Smoke samples were collected on quartz fiber filters and sent to a contract laboratory for thermal-optical analysis for organic/elemental carbon [9]. Standard precautions were taken to avoid sample contamination before sample collection by heating the filter for several hours at $700{ }^{\circ} \mathrm{C}$ and also heating the aluminum foil used to line the sample containers (petri dishes) to $500{ }^{\circ} \mathrm{C}$ for several hours. The organic fraction of the sample is determined by heating the sample in pure helium in four temperature steps up to $770^{\circ} \mathrm{C}$. The pyrolysis products flow through a heated catalyst and are converted to $\mathrm{CO}_{2}$, which is detected by nondispersive infrared spectroscopy. The second stage of the analysis consists of reducing the temperature to $525^{\circ} \mathrm{C}$ and introducing $\mathrm{O}_{2}(2 \%)$. The temperature is increased in two steps to $770{ }^{\circ} \mathrm{C}$ and the elemental carbon is oxidized to $\mathrm{CO}$ and $\mathrm{CO}_{2}$. Ultimately all of the carbon is converted to $\mathrm{CO}_{2}$ by the catalyst.

The optical absorbance of the sample is used to determine whether elemental carbon is being produced by pyrolytic conversion of the organic carbon and also to correct for this effect. The maximum deposit of elemental carbon that allows light to be transmitted through the sample is about $15 \mu \mathrm{g} / \mathrm{cm}^{2}$. As indicated in Table 5, the elemental carbon content of the smoke is over $90 \%$. The large blank reading for the high temperature filter sample may result from the diffusion of condensible organic vapors from the filter manifold onto the filter. No sample is drawn through the blank filter, but there is an open path between the manifold and the filter. The fact that the high temperature collection yields a slightly lower elemental carbon content may be an artifact resulting from vapor diffusion.

\subsection{Analysis of Polynuclear Aromatic Hydrocarbons}

Eight smoke samples weighing $10 \mathrm{mg}$ to $15 \mathrm{mg}$ each were deposited on teflon filters and were analyzed for 15 polynuclear aromatic hydrocarbons (PAH's) using combined liquid and gas chromatographic techniques. Wise and Benner from the Center for Analytical Chemistry (NBS) performed the analysis on four 
of the samples by a method previously used by them in quantifying the PAH content of two standard reference air particulate samples [10]. The PAH concentration in the smoke for samples similar to those analyzed at NBS were analyzed at the laboratories of Environment Canada in Ottawa. A preliminary analysis of heteroatomic PAHs was also made by Environment Canada.

\subsection{Sample Preparation}

At NBS the samples were spiked with internal standards (phenanthrene- $\mathrm{d}_{10}$ and 1-n-butylpyrene) and Soxhlet extracted with dichloromethane (DCM) for approximately 20 hours. The extracts were concentrated by rotary evaporation to less than $5 \mathrm{ml}$ and further concentrated under nitrogen to dryness. The residues were dissolved in $1 \mathrm{~mL}$ of $\mathrm{DCM}$ and approximately half of each extract was pipetted onto a silica cartridge (Sep-Pak, Waters, Assoc., Milford, MA) ${ }^{1}$ and eluted with $15 \mathrm{~mL}$ of a solution of $10 \%$ DCM in pentane. This chromatography is performed to isolate an enriched PAH fraction. The eluates were concentrated to dryness under nitrogen and were dissolved in $1 \mathrm{~mL}$ of a solution of 58 용 DCM in pentane. The samples were separated into subfractions by normal-phase LC on a semi-preparative amino-silane liquid chromatographic column ( $\mu$ Bondapak $\mathrm{NH}_{2}$, Waters Assoc., Milford, MA) using 5\% DCM in pentane as the mobile phase operated at a flow rate of $5 \mathrm{~mL} / \mathrm{min}$. Collection of an aromatic fraction was begun just before the elution of phenanthrene ( $30 \mathrm{~mL}$ ) and was continued until well after the elution of coronene (200 $\mathrm{mL}$ total collected). Elution volumes of these two PAHs were determined prior to sample injection. The fractionated samples were concentrated by rotary evaporation, transferred to $100 \mu \mathrm{L}$ vials, further concentrated to dryness under nitrogen and the residues dissolved in DCM.

\subsection{Gas Chromatographic Quantification}

Capillary gas chromatography with flame ionization detection (GC-FID) was used at NBS for the measurement of 15 PAHs in the four filter extracts. Each of the four extracts was chromatographed in duplicate injecting approximately $1 \mu \mathrm{L}$ onto a $30 \mathrm{~m} \times 0.25 \mathrm{~mm}$ i.d. fused silica capillary column (DB-5, $0.25 \mu \mathrm{m}$ phase thickness, J\&W Scientific, Inc.) using helium as the carrier gas (20 psi). The injector and detector temperatures were $300{ }^{\circ} \mathrm{C}$ and $320{ }^{\circ} \mathrm{C}$, respectively, and the split flow was set at $30 \mathrm{~mL} / \mathrm{min}$. The temperature program used in the study was the following: $150{ }^{\circ} \mathrm{C}$ (hold for $2 \mathrm{~min}$ ) ramp at $4^{\circ} \mathrm{C} / \mathrm{min}$ to $280^{\circ} \mathrm{C}$ (hold for $15 \mathrm{~min}$ ). The PAHs were determined by comparison of peak areas of the analytes with those of the internal standards. Typical GC-FID chromatograms for the four samples and a blank are shown in Figures 9 13. The blank (Figure 9) had been spiked with the same amount of internal standards as the samples and proved to be virtually free of any impurity except for a compound that eluted at approximately 14 minutes. Fortunately,

${ }^{1}$ Certain commercial equipment, instruments, and materials are identified in this paper to specify adequately the experimental procedure. In no case does such identification imply recommendation or endorsement by the National Bureau of Standards, nor does it imply that the material or equipment identified is necessarily the best available for the purpose. 
this artifact did not cause any difficulty in the quantification of the fifteen PAHs. The names and structures of PAHs for selected peaks in the chromatogram are given in Figure 12. It is also seen in Figure 12 that the smaller PAHs are eluted from the column first.

Environment Canada has made a preliminary analysis for nitrogen containing PAHs by GC analysis with a phosphorous detector. In sample 7,\#2, the following results were obtained: nitro-fluorene (15 $\mu \mathrm{g} / \mathrm{g})$, nitro-anthracene (5 $\mu \mathrm{g} / \mathrm{g})$, nitro-fluoranthene $(14 \mu \mathrm{g} / \mathrm{g})$, and nitro-benzo[a]pyrene (7 $\mu \mathrm{g} / \mathrm{g})$. Nitrogen containing PAHs were not detected in the other samples, presumably, because the concentrations were below the $4 \mu \mathrm{g} / \mathrm{g}$ detection limit of the analysis technique. No evidence of nitrogen containing PAHs was found in the crude oil itself at a detection limit of about $0.2 \mu \mathrm{g} / \mathrm{g}$.

\subsection{Results and Discussion}

Concentrations of 18 PAHs are shown in Tables 6 and 7 based on results from both NBS and Environment Canada (EC). The NBS results for the samples collected at the higher temperature ( $\mathrm{H}-2, \# 1$ and $\# 2$ ) suggest some preferential losses of the more volatile $\mathrm{PAH}$ during sample work-up since the concentrations calculated versus phenanthrene- $d_{10}$ were a factor of two greater than those calculated versus 1-n-butylpyrene. One has difficulty explaining these apparent losses, since the samples were prepared in the same manner as the ambient temperature samples, which showed good agreement between concentrations calculated using the two internal standards. Reported concentrations of phenanthrene for $\mathrm{H}-2$ were calculated using phenanthrene- $\mathrm{d}_{10}$ as the internal standard, since its volatility is similar to that of phenanthrene. In all other cases, 1-n-butylpyrene was used.

The analysis performed by EC involved spiking the samples with 5 internal standards: anthracene- $d_{10}$, pyrene $-d_{10}$, benz $[a]$ anthracene $-d_{12}$, perylene $-d_{12}$, and fluoranthene- $\mathrm{d}_{10}$. The recovery percent used in the analysis was the average of the first four internal standards given above and corresponded to a value of 60 to $70 \%$. The recovery percent of fluoranthene- $\mathrm{d}_{10}$ was $20 \%$ to $60 \%$ larger than the other standards and was not included. Generally speaking, there was more variability in the recovery percent for these smoke samples than is typically observed by EC for other samples.

Two diluted samples were collected simultaneously throughout most of the 900 second test in order to obtain enough sample for analysis. This is the reason for the good agreement between $C-5, \# 1$ and $C-5, \# 2$ and between $C-7, \# 1$ and $C-7, \# 2$ in Table 7. The high temperature samples were obtained sequentially. It appears from Table 6 that the sample $\mathrm{H}-2, \# 2$ and sample $\mathrm{H}-4, \# 2$, which are collected in the latter part of the burn, are enriched in the larger, lower vapor pressure PAHs.

It is apparent from both the Figures 10-13 and Tables 6 and 7 that the samples collected at the lower temperature are enriched in PAH content. The sum of selected PAH concentrations for 12 species listed in Table 7 is 4200 to $4800 \mu \mathrm{g} / \mathrm{g}$ smoke for the diluted sample and 900 to $2700 \mu \mathrm{g} / \mathrm{g}$ smoke for the high temperature collection. For the three and four ring PAHs, the enrichment for the lower temperature sample is at least a factor of 15 greater than the high 
temperature samples based on the NBS analysis and a factor of 3-20 enrichment base on EC. The enrichment in anthracene and fluoranthene observed in these tests is at least a factor of 2 greater than observed for PAH collected as a function of filter temperature in the laminar premixed sooting combustion of benzene [11].

The agreement between the NBS and EC results for the diluted samples is typically 10-208 with Indeno[1,2,3-cd]pyrene as the one exception. There is also a significant difference between laboratories for this species for the high temperature collection. Overall the EC results for the high temperature collection are about twice the NBS results with the largest differences observed for the smaller PAHs.

It is expected that the diluted samples better represent the chemistry of smoke collected downwind of a crude oil burn given the cooling the smoke would naturally experience as the smoke plume rises up and entrains air. The combustion conditions including flame size, availability of $\mathrm{O}_{2}$, and the degree of mixing together with the fuel chemistry have been shown to affect the $\mathrm{PAH}$ emission [11].

It is known that the crude oil fuels themselves have a PAH component. It is of interest to compare the amount of selected PAHs per gram of fuel versus the amounts of PAHs collected in the smoke per gram of fuel consumed. As seen in Table 8 , the relative concentration of the individual PAHs compounds is different in the fuel compared to the smoke. Overall, for the compounds measured, the total PAH content of the smoke and the original oil burned are nearly equal. For example, the concentration of phenanthrene plus anthracene in the fuel $(296 \mu \mathrm{g} / \mathrm{g}$ ) is about 2 times greater than for the smoke $(133 \mu \mathrm{g} / \mathrm{g}$ fuel burned), while the concentration of benzo[a]pyrene (BaP) is a factor of three lower for the fuel $(5 \mu \mathrm{g} / \mathrm{g}$ ) compared to the smoke $(18 \mu \mathrm{g} / \mathrm{g})$. This indicates that the combustion process itself is generating specific PAHs and that the PAH content of the fuel will not represent the distribution of PAHs emitted. There is about a four-fold enrichment of the four-six ring PAHs in the smoke compared to the crude oil.

$\mathrm{BaP}$ has been used as a surrogate for the overall carcinogenic effect of PAHs. The higher $\mathrm{BaP}$ concentration in the smoke relative to the fuel is of environmental concern; however, several key issues must be addressed before a full assessment of $\mathrm{PAH}$ emission can be made. The effect of burning rate on $\mathrm{PAH}$ emission should be analyzed. Smoke was not collected during the very rapid burning stage near the end of a test, but this burning phase may be dominant in a large fire with a thin oil layer. Preliminary data indicate for the first time the existence of nitrogen-containing PAHs in smoke from burning crude oil. The concentration is apparently low being at the lower limit of the present analysis, so that additional analysis at great resolution is need to clearly evaluate the present findings. An analysis of the vapor phase PAHs should be made to complete the present analysis that has concentrated on condensed phase products.

\subsection{PLUME DISPERSAL ANALYSIS}

The object of this analysis is to develop a methodology which will permit the prediction of smoke dispersal generated by one or more oil spill fires in 
close proximity. In order to allow for the possibility of large composite fires, there are three main ingredients that must be taken into account in the analysis. They are the stratification of the atmosphere, ambient winds, and the properties of the initial fire plume. The scale of the phenomena to be considered is roughly $1-3$ kilometers in the vertical (the plume rise height), a comparable spread laterally in a direction perpendicular to the ambient wind, and anywhere from 20 to 200 kilometers in the downwind direction.

Given the scale of these plumes, the Reynolds or Grashof numbers of the associated flow patterns are enormous, so a description which omits molecular diffusion of mass, momentum and energy is reasonable. The transport of smoke aerosol, the object of primary interest, is dominated by large scale advection. We are not concerned with the initial establishment of the plumes, so that a steady state picture of the dispersal process is appropriate. Under these circumstances the equations expressing the conservation of mass, momentum, and energy in the flow take the form:

$$
\begin{gathered}
(\overrightarrow{\mathrm{U}} \cdot \nabla) \rho+\rho \nabla \cdot \overrightarrow{\mathrm{U}}=0 \\
\rho\{(\overrightarrow{\mathrm{U}} \cdot \nabla) \overrightarrow{\mathrm{U}}\}+\nabla \mathrm{P}-\rho \overrightarrow{\mathrm{G}}=0 \\
\rho \mathrm{C}_{\mathrm{p}}(\overrightarrow{\mathrm{U}} \cdot \nabla) \mathrm{T}-(\overrightarrow{\mathrm{U}} \cdot \nabla) \mathrm{P}=0
\end{gathered}
$$

Here $\rho, \vec{U}, P$, and $T$ are respectively the density, velocity, pressure and temperature in the atmosphere. The quantity $\vec{g}$ is the gravitational acceleration and $C_{p}$ the specific heat of the gas. The conservation laws are supplemented by an equation of state

$$
\mathrm{P}=\rho \mathrm{RT}
$$

This system of equations must be solved subject to boundary conditions which introduce the three ingredients which characterize the flow of interest. The ambient atmosphere is stratified with a scale height $\mathrm{H}$ given by:

$$
\mathrm{H}=\mathrm{P}_{\mathrm{o}} / \rho_{\mathrm{o}} \mathrm{g}
$$

Here, the subscript indicates reference sea level values. The ambient atmosphere is assumed to vary on a larger scale in the horizontal directions than any length scale of interest in this study. The atmosphere then will depend only upon the vertical variable in the form $\mathrm{y} / \mathrm{H}$. Thus, far from any fire plume:

$$
\begin{aligned}
& \mathrm{P}=\mathrm{P}_{0} \hat{\mathrm{P}}_{\mathrm{a}}(\hat{\mathrm{y}}) \\
& \rho=\rho_{0} \hat{\rho}_{\mathrm{a}}(\hat{\mathrm{y}}) \\
& \hat{\mathrm{y}}=\mathrm{y} / \mathrm{H}
\end{aligned}
$$


The ambient wind is assumed to vary with height but flow in a constant direction. The wirdward direction is the $x$-direction, the vertical coordinate is $\mathrm{y}$, and the lateral direction perpendicular to $\mathrm{x}$ and $\mathrm{y}$ is $\mathrm{z}$. The corresponding velocity components are $\mathrm{u}, \mathrm{v}, \mathrm{w}$. Thus:

$$
\begin{aligned}
& \overrightarrow{\mathrm{x}}=(\mathrm{x}, \mathrm{y}, \mathrm{z}) \\
& \overrightarrow{\mathrm{U}}=(\mathrm{u}, \mathrm{v}, \mathrm{w})
\end{aligned}
$$

The boundary condition far from any plume can then be expressed in the form:

$$
\begin{aligned}
& \mathrm{u}=\mathrm{U}_{\mathrm{o}} \hat{\mathrm{u}}_{\mathrm{a}}(\mathrm{y}) \\
& \mathrm{v}=\mathrm{w}=0
\end{aligned}
$$

Finally, the input from the fire plumes must be prescribed. It is not possible to calculate anything in or near the combustion zone based on equations (3) and (4), since the small scale physical and chemical processes are not described by these equations. There is no point appending the additional terms required, since we cannot even solve the above equations without further approximation. Instead, the vertical velocities and temperatures characteristic of a fire of prescribed strength are used as input variables. McCaffrey [12] has developed a set of correlations for fire plume velocities and temperatures which are ideal for this purpose. These correlations have been used to calculate inflow velocities into oil spill fires by the authors [1]. The time average vertical velocity and temperature distributions have the form:

$$
\begin{aligned}
& \mathrm{v}=(\mathrm{gD})^{1 / 2} \mathrm{~V}(\mathrm{y} / \mathrm{D}) \exp \left[-(\mathrm{r} / \mathrm{R})^{2}\right] \\
& \left(\mathrm{T}-\mathrm{T}_{0}\right) / \mathrm{T}_{0}=\theta(\mathrm{y} / \mathrm{D}) \exp \left[-\alpha(\mathrm{r} / \mathrm{R})^{2}\right] \\
& \mathrm{D}=\left(\mathrm{Q} / \rho_{0} C_{\mathrm{p}} \sqrt{\mathrm{g}}\right)^{2 / 5} \\
& \mathrm{r}^{2}=\left(\mathrm{x}-\mathrm{x}_{\mathrm{c}}\right)^{2}+\left(\mathrm{z}-\mathrm{z}_{\mathrm{c}}\right)^{2}
\end{aligned}
$$

Here $Q$ is the total rate of heat release from the fire centered at $\left(x_{c} z_{c}\right)$. The plume centerline velocity $V(y / D)$, temperature $\theta(y / D)$, and width $R(y / D)$, together with the ratio of velocity to thermal profile with $\alpha$ are given by McCaffrey [12].

Note that there is no need to use these plume input functions at ground level. In practice, it would be desirable to select an attitude $y_{0}$ where the excess temperature is sufficiently small and the plume sufficiently broad that equations ( 3 ) can be adequately solved in the presence of the wind that disperses the plume. As $y_{0}$ increases, this condition becomes easier to meet for a given fire (or fires). On the other hand, we wish to begin the calculation at an altitude sufficiently low so that the wind has not yet had much of an effect on the plume, and distinct fire plumes have not yet merged. 
For individual fires in the range $10^{2}-10^{3} \mathrm{MW}$, this altitude should typically be in the range $50-150 \mathrm{M}$.

As mentioned above, it is necessary to simplify equations (3) if reasonably accurate numerical solutions are to be obtained without prodigious computational efforts. As a practical matter, it is much easier to solve these equations if the numerical method can march in the direction of the wind and solve a two-dimensional problem in each cross flow plane. Moreover, we would like to reduce the equations to an equivalent incompressible form previously used to study flows generated by enclosure fires $[13,14]$. To this end, it is more convenient to work with the potential temperature $\theta$, rather than the cemperature itself. By definition we have:

$$
\mathrm{T} \equiv \mathrm{T}_{0}\left(\mathrm{P} / \mathrm{P}_{0}\right)(\gamma-1) / \gamma \quad \theta
$$

The energy equation and equation of state now take the following form:

$$
\begin{aligned}
& (\overrightarrow{\mathrm{U}} \cdot \nabla) \theta=0 \\
& \left(\mathrm{P} / \mathrm{P}_{\mathrm{o}}\right)^{1 / \gamma}=\left(\rho / \rho_{0}\right) \theta
\end{aligned}
$$

In order to simplify the equations to the form desired, we introduce dimensionless dependent variables and a small parameter $\delta$ as follows:

$$
\begin{aligned}
& \theta=1+\delta \hat{\theta}_{\mathrm{A}}(\hat{\mathrm{y}})+\delta \theta(\hat{x}, \hat{y}, \hat{z})+\cdots \\
& \rho / \rho_{0}=\hat{\rho_{\mathrm{A}}}(\hat{\mathrm{y}})+\hat{\rho}(\hat{\mathrm{x}}, \hat{\mathrm{y}}, \hat{\mathrm{z}})+\cdots \\
& P / P_{0}=\hat{P}_{A}(\hat{y})+\delta \hat{P}(\hat{x}, \hat{y}, \hat{z})+\cdots \\
& (v, w)=V_{0}(\hat{v}[\hat{x}, \hat{y}, \hat{z}]+\cdots, \hat{w}[\hat{x}, \hat{y}, \hat{z}]+\cdots) \\
& u=U_{\circ}\left\{1+\delta^{2} \hat{u_{A}}(\hat{y})+\delta^{2} \hat{u}(\hat{x}, \hat{y}, \hat{z})+\cdots\right\}
\end{aligned}
$$

The parameter $\delta$ is defined by the relations:

$$
\begin{aligned}
& \delta=\mathrm{Q} / \rho_{0} \mathrm{CpT}_{0} \mathrm{H}^{2} \mathrm{~V}_{0} \\
& \mathrm{H}=\mathrm{P}_{0} / \rho_{\mathrm{o}} \mathrm{g} \\
& \mathrm{V}_{\mathrm{o}}=\left(\mathrm{Qg}^{2} / \mathrm{P}_{\mathrm{o}} \mathrm{CpT}_{0}\right)^{1 / 3}
\end{aligned}
$$


Finally, the independent variables are defined in terms of the scale height and $\delta$ :

$$
\mathrm{x}=(\mathrm{H} / \delta) \hat{\mathrm{x}}, \mathrm{y}=\hat{\mathrm{Hy}}, \mathrm{z}=\hat{\mathrm{Hz}}
$$

We also assume that the ambient wind $U_{0}$ is much larger than $V o$ by a factor of order of magnitude $\delta$. Thus we can introduce a parameter $\mathrm{K}$ of order unity in $\delta$ such that:

$$
\mathrm{V}_{\circ}=\delta \mathrm{KU}_{0}
$$

The scaling laws implied by the expansion defined in equations (11)-(14) are consistent with the following physical picture. The atmospheric motion is nearly but not quite adiabatic. The small excess temperature remaining in the plume and departures in the ambient atmosphere from neutral stability (adiabaticity) are responsible. Similarly, the atmospheric winds are nearly uniform and much larger than the vertical buoyancy induced velocity. However, since we are interested in downwind dispersal over distances much larger than the plume rises, the buoyancy effects cannot be neglected. When all these relations are substituted into the first two of equations (3) and equations (10), the following dimensionless system results:

$$
\begin{aligned}
& \frac{\partial \hat{v}}{\partial \hat{y}}+\frac{\partial \hat{w}}{\partial \hat{z}}+\frac{d \log \hat{\rho}_{A} \hat{v}}{d \hat{y}}=0 \\
& \frac{\partial \hat{v}}{\partial \hat{t}}+\hat{v} \frac{\partial \hat{v}}{\partial \hat{y}}+\hat{w} \frac{\partial \hat{v}}{\partial \hat{z}}+\frac{\partial \Phi}{\partial y}-\hat{\theta}=0 \\
& \frac{\partial \hat{v}}{\partial \hat{t}}+\hat{v} \frac{\partial \hat{v}}{\partial \hat{y}}+\hat{w} \frac{\partial \hat{v}}{\partial \hat{z}}+\frac{\partial \Phi}{\partial \hat{z}}=0 \\
& \frac{\partial \hat{\theta}}{\partial \hat{t}}+\hat{v} \frac{\partial \hat{\theta}}{\partial \hat{y}}+\hat{w} \frac{\partial \hat{\theta}}{\partial \hat{z}}+\hat{v} \frac{\partial \hat{\theta}_{A}}{\partial \hat{y}}=0
\end{aligned}
$$

Two new variables have been introduced into equations (15). They are:

$$
\begin{aligned}
& \hat{t}=K \hat{x} \\
& \Phi=\left\{-\int_{0}^{\hat{y}} \rho_{A}(\hat{y}) \Phi_{A}(\hat{y}) d \hat{y}+\hat{P}\right\} / \rho_{A}
\end{aligned}
$$


Those final substitutions have generated a system of equations very close to those solved by Baum et.al. [13]. The system is now explicitly two dimensional and time dependent with suitably scaled distance downwind playing the role of time. There are two significant differences, which will require modifications to earlier calculations before quantitative predictions can be made. First, the ambient stratification as by $\hat{\theta}_{A}$ and $\rho_{A}$ appear in the equations in a fundamental way. Second, the enclosure walls built into the calculations in Ref. [13] must be removed. Still, the equations are close enough that it is worthwhile to see the kind of results which emerge from a related enclosure fire computation.

In order to make the calculations equivalent, we consider the problem of a "thermal" generated in the enclosure. To see why this is necessary consider the "floor" boundary conditions represented by equations (8). Since $x$ is now the time like variable, the Gaussian forms used to represent the velocity and temperature profiles imply that the vertical velocity and temperature introduced at the floor of the two dimensional enclosure must be turned on and off rapidly. Figure 14 shows (potential) temperature contours shortly after the pulse is turned on. Recalling that the frame of reference is now a plane sweeping downstream with the ambient wind velocity, Figure 15 shows the plume just downwind of the fire. It is now bent over and barely connected to the "ground". Figure 16 shows the initial development of the typical counterrotating vortex pair in the plume as it rises above the datum level much further downstream. Finally, in Figure 17 the vortex structure is quite pronounced. The plume structure this distance downstream would probably be strongly modified by stratification and the presence of plumes generated by other fires. Some indication of the latter effect might be inferred by considering this sequence to represent an infinite periodic array of plumes aligned perpendicular to the wind. However, definitive answers can only come from calculations based exactly on equations (15) with appropriate boundary conditions. Future work will focus on this problem.

\subsection{SUMMARY}

An experimental facility was completed to examine the burning conditions of crude oil in a $1.2 \mathrm{~m}$ diameter pool fire configuration. This facility permitted controlled burning experiments to be conducted under conditions representative of the radiation-dominated, turbulent flow regime of larger pool fires that might occur on the open ocean or in pools confined by broken ice. Tests with three different crude oils, Alberta Sweet, La Rosa, and Murban were conducted using initial oil depths of $2 \mathrm{~mm}, 4 \mathrm{~mm}, 10 \mathrm{~mm}$ and $25 \mathrm{~mm}$ floated on a deep water layer.

At oil depths of $10 \mathrm{~mm}$ and $25 \mathrm{~mm}$ each oil exhibited two distinct burning stages. The first was associated with a progressive vaporization of the burning oil layer and the other with more intense, short duration burning in which the oil surface was churned and splattered by boiling water under the thin oil layer. For Murban crude oil, the steady burning resulted in energy release rates of $840 \mathrm{~kW} / \mathrm{m}^{2}$ which increased to $1860 \mathrm{~kW} / \mathrm{m}^{2}$ during the vigorous burning before extinction. Residual oil left on the water surface at the end of natural burning corresponded to a uniform layer depth of $0.6 \mathrm{~mm}$ to $1.2 \mathrm{~mm}$. 
The rate of heat conduction into the oil during burning was estimated to be less than 20 percent of the incident radiant energy directed at the surface. Additional tests are planned to characterize the radiation to the oil surface. Several instrumentation problems must be overcome in order to obtain more reliable data. This new data will be used in an analysis of the surface energy balance for the burning crude oil.

The burning of Alberta Sweet crude oil results in a high smoke emission with $\epsilon$ about 0.10 (10\% conversion to smoke). The smoke has a high elemental carbon component in excess of 908 resulting in a highly absorbing soot with a specific extinction coefficient, $\mathrm{K}_{\mathrm{s}}$, of $9.4 \mathrm{~m}^{2} / \mathrm{g}$. These values are similar to the values reported last year for Prudhoe Bay crude oil. Over the 900 second period of burning, the values of both $\epsilon$ and $K_{f}$, the specific extinction coefficient relative to the fuel, increase and also the PAH emission shifts from smaller to larger structures as the fuel burns. Perhaps all of these effects are a result of a fractionation of the fuel with the sootier component burning last.

The primary gaseous product of combustion is $\mathrm{CO}_{2}$ with the $\mathrm{CO}$ concentration about a factor of 25 lower than $\mathrm{CO}_{2}$. The emission of $\mathrm{NO}$ and $\mathrm{NO}_{\mathrm{x}}$ are less than one thousandth the concentration of $\mathrm{CO}_{2}$.

Independent analyses of the PAH content of the smoke by the National Bureau of Standards and Environment Canada showed the same trends and had good overall agreement for 12 individual PAHs. The PAH content of the smoke was nearly equal to that in the original oil burned. The PAH content of the smoke was enriched in the larger species in comparison with the fuel. The concentration of benzo[a]pyrene, which is often used as a surrogate for the carcinogenic effect of $\mathrm{PAH}$, was found to be three times greater in the crude oil smoke per gram of fuel consumed compared to the crude oil itself. The concentrations of the three ring PAHs were found to be very sensitive to the filter collection temperature. Thus, it is important to use a diluter when sampling the PAHs to simulate the conditions existing in a rising smoke plume.

Nitrogen containing PAHs have been observed in one of four crude oil smoke samples at concentrations near the lower limit of detection for the present analysis. This is a preliminary result obtained by Environment Canada and additional higher resolution analysis is needed.

An analysis of the dispersal of fire plumes by atmospheric winds was presented. It was demonstrated that as the plume buoyancy weakens with altitude and the plume gets bent over by ambient winds, the equations describing the dispersal process are greatly simplified. Physically, they are equivalent to studying the two-dimensional but time dependent process by which a buoyant thermal equilibrates with a stratified atmosphere at rest. Sample results of a similar process occurring inside an enclosure have been shown. This approximate model can be used to calculate realistic dispersion of oil spill combustion generated smoke with moderate sized computing resources. 


\subsection{ACKNOWLEDGEMENT}

This work was supported under the joint sponsorship of the Minerals Management Service, U.S. Department of the Interior, Environmental Protection Service, Environment Canada, and the Office of Research and Development, U.S. Coast Guard.

Special thanks is extended to Mr. Edward Tennyson who was instrumental in organizing this program of research. Dr. M. F. Fingas was especially helpful in consultations about the chemistry and analysis of crude oils. The assistance of $\mathrm{Mr}$. B. Benner and $\mathrm{Dr}$. S. Wise was indispensible in the analysis for $\mathrm{PAH}$ compounds in the crude oil and soot.

The authors also wish to thank the many individuals on the CFR staff involved with the large scale testing effort among them were Dr. K. M. Tu, Mr. N. Bryner, Mr. J. S. Steel, and Mr. R. Zile.

\subsection{REFERENCES}

1. Evans, D., Baum, H., McCaffrey, B., Mulholland, G., Harkleroad, M., and Manders, W., "Combustion of Oil on Water", NBSIR 86-3420, National Bureau of Standards, Center for Fire Research, Gaithersburg, MD 20899, (1986).

2. Huggett, C., Fire and Materials 4, 61 (1980).

3. Bobra, M. A. and Chung, P.T., "A Catalogue of Oil Properties," Environment Canada Report No. EE-77, March 1986.

4. Healy, J. J., de Groot, J. J., and Kestin, J., Physica 82C, 392 (1982)

5. Yumoto, $\mathrm{T}$, "Heat Transfer from Flame to Fuel Surface in Large Pool Fires," Combustion and Flame, 17, 108-110 (1970).

6. Petty, S. E. "Combustion of Crude Oil on Water," Fire Safety Journal, $\underline{5}$, $123-134$ (1983).

7. Brosmer, M. A. and Tien, C. L. "Radiative Energy Blockage in Large Pool Fires," Combustion Science and Technology, 51, 21-37, 1987.

8. Boyland, E., The Toxicology of Soot, Soot in Combustion Systems and its Toxic Properties, ed. by J. Lahaye and G. Prado, Plenum Press, New York, $13,1981$.

9. Johnson, R. L., Shah, J. J., Cary, R. A., and Huntzicker, J. J., An Automated Thermal-Optical Method for the Analysis of Carbonaceous Aerosol, in ACS Symposium Series, No. 167, Atmospheric Aerosol: Source/Air Quality Relationships, ed. by E. S. Macias and P. K. Hopke, 1981 . 
10. Wise, S. A., Benner, B. A., Chesler, S. N., Hilpert, L. R., Vogt, C. R., and May W. E., Characterization of the Polycyclic Aromatic Hydrocarbons from Two Standard Reference Material Air Particulate Samples, Anal. Chem., 58, 3068, (1986).

11. Longwell, J. P., Polycyclic Aromatic Hydrocarbons and Soot from Practical Combustion Systems, Soot in Combustion Systems and its Toxic Properties, ed. by J. Lahaye and G. Prado, Plenum Press, New York, 37, 1981.

12. McCaffrey, B.J., "Momentum Implications for Buoyant Diffusion Flames", Combustion and Flame $\underline{52}, 149$ (1983).

13. Baum, H.R., Rehm, R.G., and Mulholland, G.W., "Computation of Fire Induced Flow and Smoke Coagulation", Nineteenth Symposium (International) on Combustion, The Combustion Institute, Pittsburgh, 921 (1982).

14. Baum, H.R., and Rehm, R.G., "Calculations of Three Dimensional Buoyant Plumes in Enclosure", Combustion Science and Tech. 40, 55, (1984). 
TABLE 1

PROPERTIES OF OILS (TYPICAL DATA)

CRUDE OIL

$$
\text { DENSITY }
$$

$\mathrm{kg} / \mathrm{m}^{3}$
PERCENTAGE BY WEIGHT AROMATICS WAX

12.8

23.2

16.6

81.4

66.1

9.9

ASPHALTENES

\section{ALBERTA SWEET *}

LA ROSA

911

824

MURBAN

-............

1.8

6.2

Composition analysis provided by Environment Canada 
0
$z$
$z-1$
0
0
0
21
-1
-1
0
0

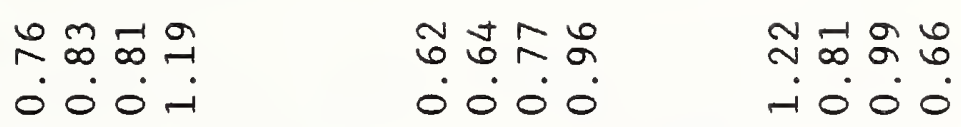

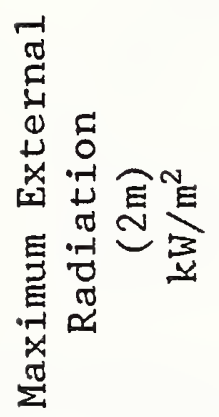

Nom n

$\therefore \rightleftharpoons$ ב

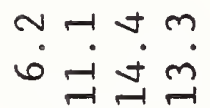

$0 \forall \infty 0$

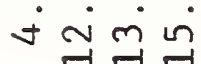

คี

$\sum^{\pi}$

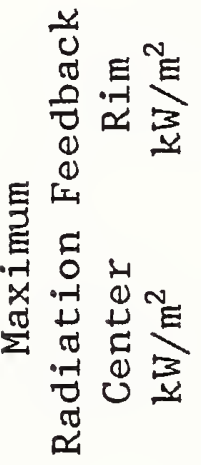

$\checkmark-100$

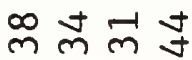

m.

$\infty \infty \infty \sim$

ज्ञ ' 品

이요 유

.

$\stackrel{\pi}{\stackrel{\pi}{ \pm}}$

a

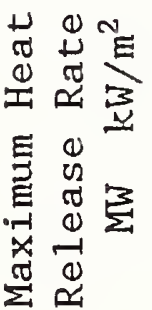

응오응을

어

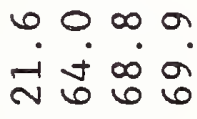

$\infty \sim 0 m$

กี่

$\sim \ln \infty \checkmark$

ำ

융으긍

- $\sim$ N

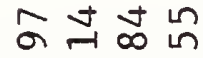

은요은

$\infty \underset{-1}{2}$

ำ 슨

بु

苟

० $\sim \mathcal{N}$

ㅇํำ

Oें

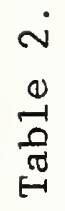

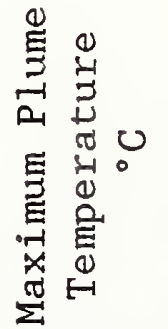

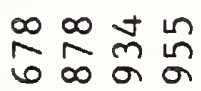

$\hat{\circ} \circlearrowleft$

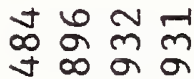

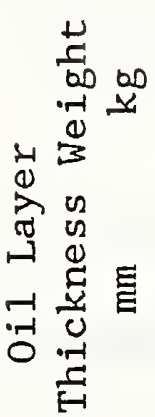

ปุ

-ن்

क

\&워 ง

- ذं

$\sim$ 눙

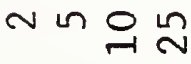

N $\ln ㅇ ㅡ ㄴ$

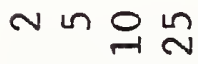

$\underset{⿱ 亠 䒑}{0}$ 


\begin{tabular}{|c|c|c|c|c|c|}
\hline Property & $\begin{array}{l}\text { Test } H-1 \\
\text { sample } 1\end{array}$ & $\begin{array}{l}\text { Test } H-1 \\
\text { sample } 2\end{array}$ & $\begin{array}{l}\text { Test } \mathrm{H}-4 \\
\text { Sample } 1\end{array}$ & $\begin{array}{l}\text { Test H- } 4 \\
\text { sample } 2\end{array}$ & average \\
\hline $\mathrm{dQ} / \mathrm{dt}, \mathrm{kW}$ & 217 & 172 & 234 & 191 & 204 \\
\hline $\mathrm{dm} / \mathrm{dt}, \mathrm{g} / \mathrm{s}$ & 5.27 & 4.40 & 5.63 & 4.93 & 5.06 \\
\hline $\mathrm{H}, \mathrm{KJ} / \mathrm{g}$ & 37.4 & 39.8 & 41.7 & 38.8 & 39.4 \\
\hline$\epsilon_{1}$ & 0.076 & 0.119 & 0.100 & 0.110 & 0.101 \\
\hline$\epsilon_{2}$ & 0.070 & 0.110 & 0.089 & 0.101 & 0.093 \\
\hline $\mathrm{K}_{\mathrm{s}}, \mathrm{m}^{2} / \mathrm{g}$ & 9.2 & 9.3 & $(6.4)$ & 9.8 & 9.4 \\
\hline $\mathrm{K}_{\mathrm{f}}, \mathrm{m}^{2} / \mathrm{g}$ & 0.70 & 1.10 & 0.64 & 1.08 & 0.88 \\
\hline
\end{tabular}

\section{Property}

$\mathrm{dQ} / \mathrm{dt}, \mathrm{kW}$

$\mathrm{dm} / \mathrm{dt}, \mathrm{g} / \mathrm{s}$

$\mathrm{H}, \mathrm{KJ} / \mathrm{g}$

$\epsilon_{1}$

$\epsilon_{2}$

$\mathrm{K}_{\mathrm{s}}, \mathrm{m}^{2} / \mathrm{g}$

$\mathrm{K}_{\mathrm{f}}, \mathrm{m}^{2} / \mathrm{g}$
Test $\mathrm{C}-5$

205

4.98

41.1

0.087

0.080

10.2

0.88

Legend:

H-1 and H-4 refer to identical crude oil burns in which the filter collection system was heated to about $100^{\circ} \mathrm{C}$.

C-5 and C-7 refer to identical crude oil burns in which the smoke is cooled to ambient temperature in a sampling dilution system.

$\mathrm{dQ} / \mathrm{dt}$ - heat release rate of the fuel.

$\mathrm{dm} / \mathrm{dt}$ - burning rate of the fuel.

$\mathrm{H}$ - heat of combustion.

$\epsilon_{1}$ and $\epsilon_{2}$ refer to the smoke yield based on a flux method and a carbon balance method [1], respectively.

$\mathrm{K}_{\mathrm{f}}$ and $\mathrm{K}_{\mathrm{s}}$ are defined in the section entitled Smoke Emission Measurements. 
TABLE 4. GASEOUS EMISSION FROM ALBERTA SWEET CRUDE OIL

$\begin{array}{lllll}\text { Species } & \begin{array}{l}\mathrm{C}-6 \\ \mathrm{Dpm}\end{array} & \begin{array}{l}\mathrm{C}-7 \\ \mathrm{Dpm}\end{array} & \begin{array}{c}\mathrm{C}-6 \\ \text { fract. }\end{array} & \begin{array}{c}\mathrm{C}-7 \\ \mathrm{fract.}^{a}\end{array} \\ \mathrm{CO}_{2} & 4604 & 4906 & & \\ \mathrm{CO} & 174 & 187 & 0.038 & 0.038 \\ \mathrm{NO} & 0.7 & 0.7 & 1.6 \times 10^{-4} & 1.5 \mathrm{x}^{-4} \\ \mathrm{NO}_{\mathrm{x}} & 2.3 & 1.7 & 5.0 \times 10^{-4} & 4.0 \mathrm{x}^{-4}\end{array}$

a Volume fraction of gas species relative to $\mathrm{CO}_{2}$. 
TABLE 5. ORGANIC/ELEMENTAL ANALYSIS OF SMOKE FROM BURNING OF ALBERTA SWEET CRUDE OIL

$\begin{array}{lccc}\text { Sample No. } & \begin{array}{c}\text { org. carbon } \\ \mu \mathrm{g} / \mathrm{cm}^{2}\end{array} & \begin{array}{c}\text { elem. carbon } \\ \mu \mathrm{g} / \mathrm{cm}^{2}\end{array} \\ \text { H-3 }, \text { blank } & 3.80 \pm 0.46 & 0.41 \pm 0.22 & \text { \& elem. carbon } \\ \text { H-3, \#1 } & 6.18 \pm 0.51 & 29.29 \pm 1.66 & 92 \\ \text { H-3, \#2 } & 5.18 \pm 0.46 & 17.71 \pm 1.09 & 93 \\ \text { H-3, \#2 repeat } & 5.29 \pm 0.46 & 19.86 \pm 1.19 & 93 \\ \text { C-5, blank } & 0.78 \pm 0.24 & 0.22 \pm 0.21 & \\ \text { C-5, \#1 } & 0.97 \pm 0.25 & 12.95 \pm 0.85 & 99 \\ \text { C-5, \#1 repeat } & 0.80 \pm 0.24 & 13.37 \pm 0.87 & 100 \\ \text { C-5, \#2 } & 2.76 \pm 0.24 & 43.02 \pm 2.35 & 96\end{array}$

a The blank values are subtracted from the sample values in determining the percent elemental carbon.

b $\mathrm{H}$ refers to filter heated to about $100{ }^{\circ} \mathrm{C}$ and $\mathrm{C}$ to filter at near ambient conditions. 
TABLE 6. MEAN PAH CONCENTRATION FOR ALBERTA SWEET CRUDE OIL SMOKE SAMPLES COLLECTED AT $100^{\circ} \mathrm{C}^{\mathrm{a}}$

\begin{tabular}{|c|c|c|c|c|c|}
\hline No. ${ }^{b}$ & $\underline{\mathrm{PAH}}$ & $\begin{array}{l}\mathrm{H}-2, \# 1 \\
\mu \mathrm{g} / \mathrm{g}^{\mathrm{c}}\end{array}$ & $\begin{array}{l}\mathrm{H}-2, \# 2 \\
\mu \mathrm{g} / \mathrm{g}\end{array}$ & $\begin{array}{l}\mathrm{H}-4, \# 1 \\
\underline{\mu \mathrm{g} / \mathrm{g}}\end{array}$ & $\begin{array}{l}\mathrm{H}-4, \# 2 \\
\mu \mathrm{g} / \mathrm{g}\end{array}$ \\
\hline & Acenaphthylene & & & 3 & 2 \\
\hline & Acenaphthene & & & N.D. & N.D. \\
\hline & Fluorene & & & 4 & 3 \\
\hline 1. & Phenanthrene & $31^{d}$ & $21^{d}$ & & \\
\hline 2. & Anthracene & & N.D. & $94^{8}$ & $58^{8}$ \\
\hline 3. & Fluoranthene & 47 & 37 & 213 & 126 \\
\hline 4. & Acephenanthrylene & 22 & 22 & & \\
\hline 5. & Pyrene & 65 & 49 & 259 & 152 \\
\hline 6. & $\begin{array}{l}\text { Benzo[ghi] } \\
\quad \text { fluoranthene }\end{array}$ & 69 & 65 & & \\
\hline 7. & Cyclopenta[cd] & 24 & 108 & & \\
\hline 8. & $\begin{array}{c}\text { pyrene } \\
\text { Benz[a] anthracene }\end{array}$ & 63 & 87 & 88 & 176 \\
\hline 9. & $\begin{array}{l}\text { Chrysene/ } \\
\text { Triphenylene }\end{array}$ & 71 & 87 & 95 & 186 \\
\hline 10. & $\begin{array}{l}\text { Benzo }[b, j, k] \\
\text { fluoranthene }\end{array}$ & 187 & 351 & 491 & 515 \\
\hline 11. & Benzo[e]pyrene & 66 & 106 & 92 & 224 \\
\hline 12. & Benzo[a]pyrene & 113 & 204 & 73 & 189 \\
\hline 13. & Perylene & 19 & 38 & 18 & 52 \\
\hline 14. & $\begin{array}{l}\text { Indeno }[1,2,3-\mathrm{cd}] \\
\text { pyrene }\end{array}$ & 112 & 219 & 251 & 752 \\
\hline 15. & Benzo[ghi] perylene & 127 & 235 & 87 & 240 \\
\hline Tot & Eal PAH Conc. ${ }^{f}$ & 901 & 1434 & 1761 & 2670 \\
\hline
\end{tabular}

The samples $\mathrm{H}-2$ analyzed at NBS and $\mathrm{H}-4$ were analyzed by EC. Peak identification numbers for Figures 10-13. $\mu \mathrm{g}$ of $\mathrm{PAH} / \mathrm{g}$ of smoke; uncertainty estimated to be $\pm 10 \%$ of the reported concentration for samples $\mathrm{H}-2$.

d Concentration calculated using phenanthrene- $d_{10}$ as the internal standard; all other concentrations computed based on 1 - $n$-butylpyrene as the internal standard for samples $\mathrm{H}-2$.

e Not detected.

$f$ Only PAHs common to both analyzes (NBS and EC) are included in the sum.

$g$ This number represents the sum of penanthrene and anthracene. 
TABLE 7. MEAN PAH CONCENTRATION FOR ALBERTA SWEET CRUDE OIL SMOKE SAMPLES COLLECTED AT AMBIENT TEMPERATURE ${ }^{a}$

\begin{tabular}{|c|c|c|c|c|c|}
\hline No . ${ }^{b}$ & $\underline{P A H}$ & $\begin{array}{l}C-5, \# I \\
\mu g / g^{c}\end{array}$ & $\begin{array}{l}C-5, \# 2 \\
\mu \mathrm{g} / \mathrm{g}\end{array}$ & $\begin{array}{l}C-7, \#] \\
\mu \mathrm{g} / \mathrm{g}\end{array}$ & $\begin{array}{l}\mathrm{C}-7, \# 2 \\
\mu \mathrm{g} / \mathrm{g}\end{array}$ \\
\hline
\end{tabular}

Acenaphthylene

Acenaphthene

Fluorene

1. Phenanthrene

2. Anthracene

3. Fluoranthene

4. Acephenanthryleñe

5. Pyrene

6. Benzo[ghi]

fluoranthene

7. Cyclopenta [cd]

pyrene

8. Benz [a] anthracene

9. Chrysene/ Triphenylene

10. Benzo[b,j,k] fluoranthene

11. Benzo[e]pyrene

12. Benzo[a]pyrene

13. Perylene

14. Indeno[1,2,3-cd] 185 pyrene

15. Benzo[ghi]perylene 209

Total PAH Conc. ${ }^{\mathrm{d}}$
35

59

N.D.

1.2

126

140

1040

291

725

738

721

397

839

795

779

220

538

222

237

223

226

219

217

394

421

410

121

179

173

184

206

196

41

188

45

47

535

532

206

176

175

4186

4768

4696

a The samples C-5 were analyzed at the National Bureau of Standards and the samples C-7 were analyzed by Environment Canada.

b Peak identification numbers for Figures 10-13.

c $\mu \mathrm{g}$ of $\mathrm{PAH} / \mathrm{g}$ of smoke; uncertainty estimated to be $\pm 10 \%$ of the reported concentration for samples C-5.

d Only PAHs common to both analyzes (NBS and EC) are included in the sum.

e This number represents the sum of phenanthrene and anthracene. 
TABLE 8. COMPARISON OF PAH CONTENT OF ALBERTA SWEET CRUDE OIL AND SMOKE FROM BURNED OIL

\section{No. ${ }^{a} \underline{\mathrm{PAH}}$}

Acenaph thylene

Acenaphthene

Fluorene

1. Phenanthrene

2. Anthracene

3. Fluoranthene

4. Acephenanthrylene

5. Pyrene

6. Benzo[ghi]

fluoranthene

7. Cyclopenta [cd]

pyrene

8. Benz [a] anthracene

9. Chrysene/

Triphenylene

10. Benzo[b,j,k]

fluoranthene

11. Benzo[e]pyrene

12. Benzo[a]pyrene

13. Perylene

14. Indeno [1,2,3-cd] pyrene

15. Benzo[ghi]perylene

Total Conc. of PAHs
Crude $0 i 1$

$\mu g / g^{b}$

61

N.D.

188

$296^{d}$

22

21

N.D.

30

N.D.

21

5

N.D.

N.D.

N.D.

395
40

84

22

54

22

23

39

12

18

4

21

104

29

3

40

2

4

3

448
Smoke

$\mathrm{g} / \mathrm{g}^{\mathrm{c}}$

a Peak identification numbers for Figures 10-13.

b $\quad \mu \mathrm{g} \mathrm{PAH} / \mathrm{g}$ crude oil. Analysis performed by Environment Canada.

c $\mu \mathrm{g} \mathrm{PAH} / \mathrm{g}$ of crude oil burned assuming smoke emission factor, $\epsilon$, of 0.10 and $\mathrm{PAH}$ emission data from $\mathrm{C}-5$, \#2. Analysis performed by NBS.

d This number represents the sum of penanthrene and anthracene. 


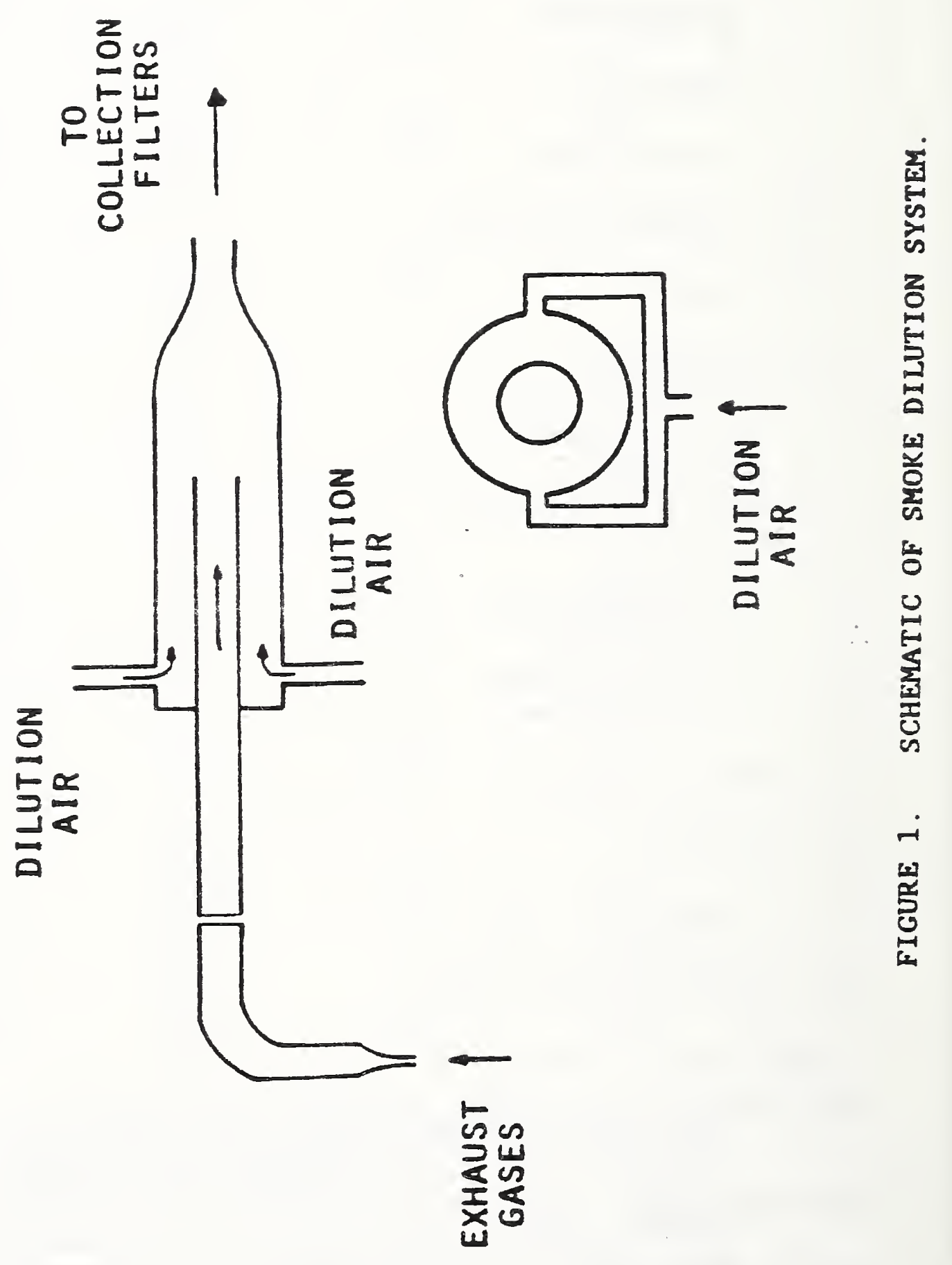




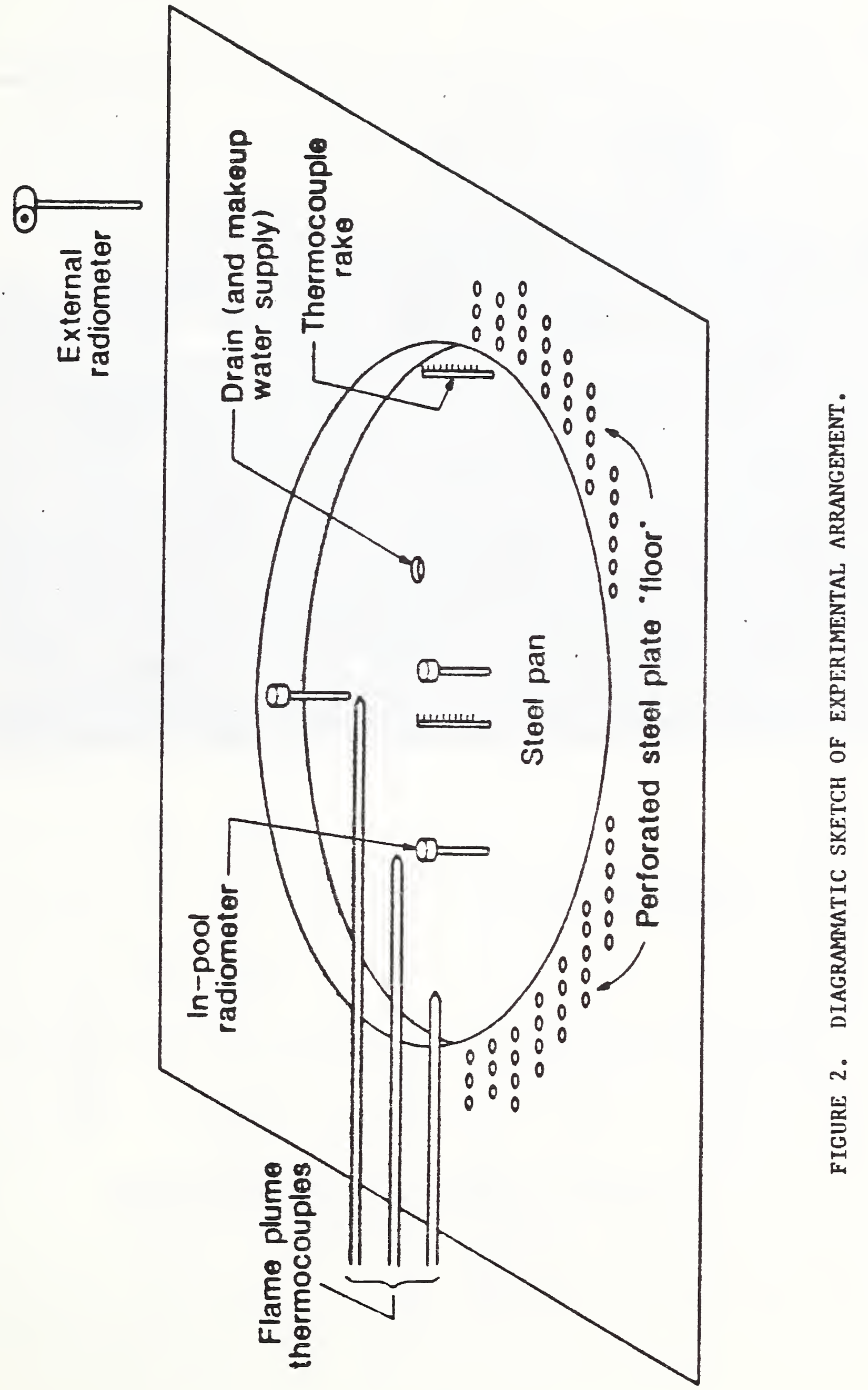




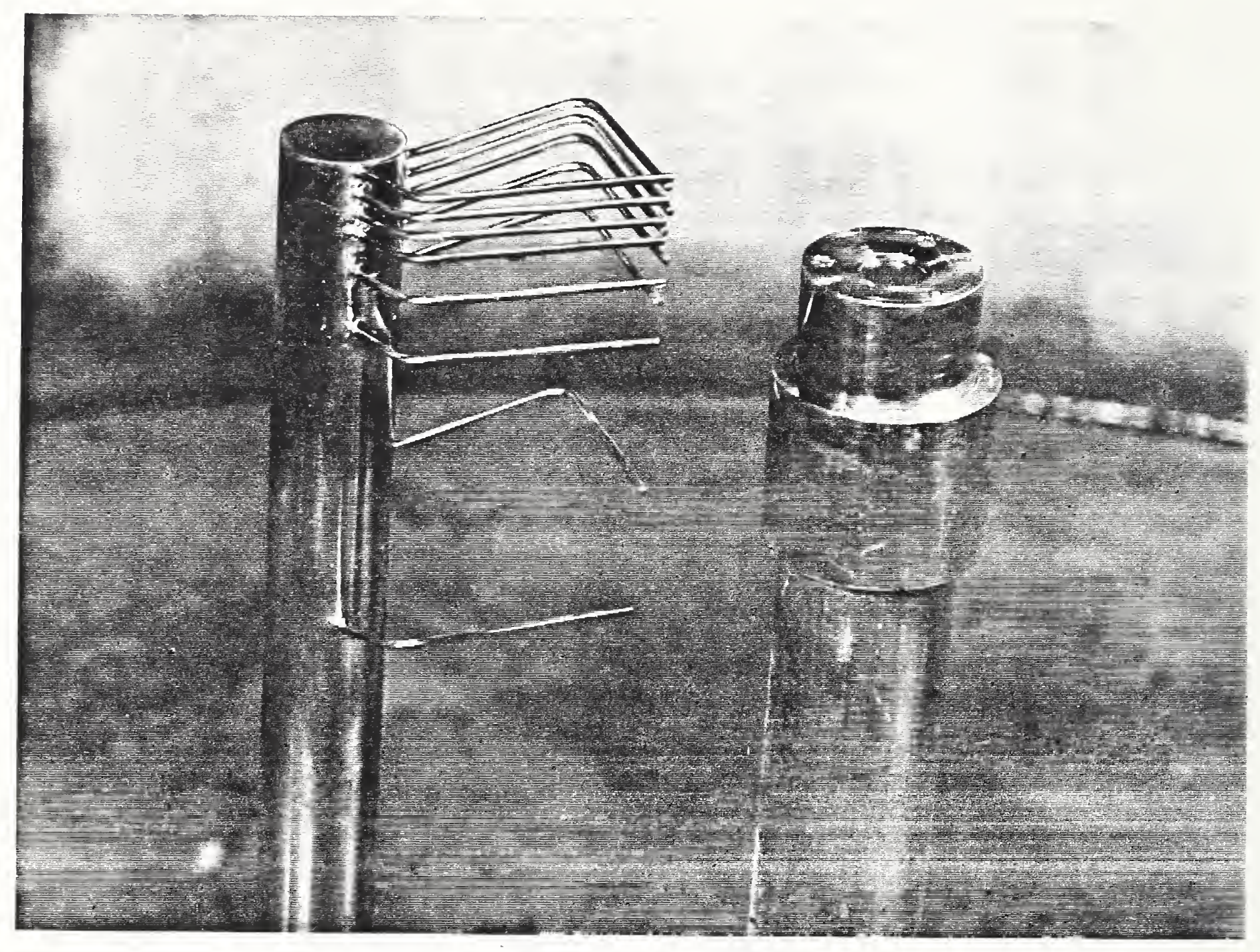

FIGURE 3. THERMOCOUPLE RAKE FOR MEASUREMENT OF OIL-WATER LAYER TEMPERATURE. 


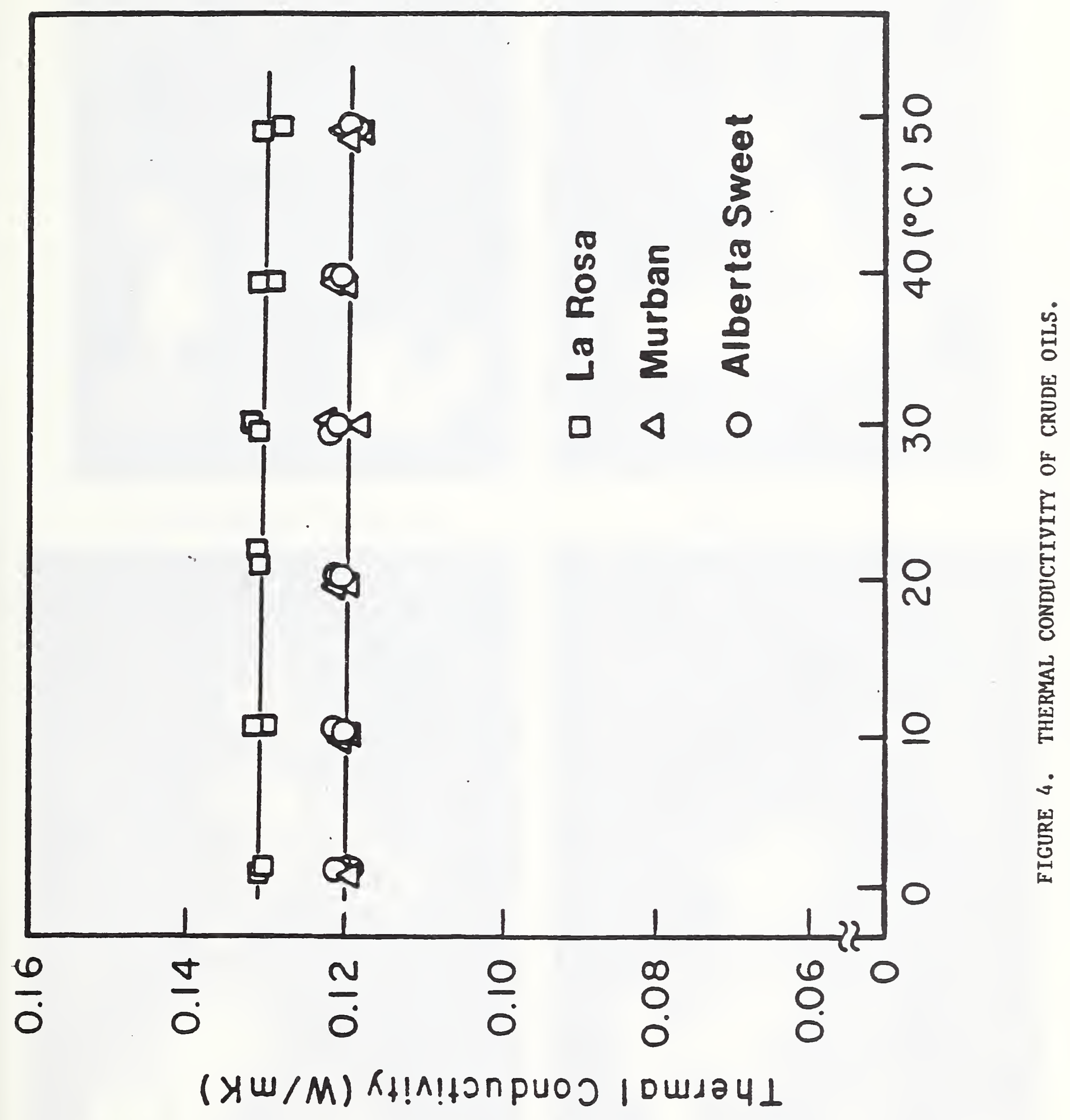




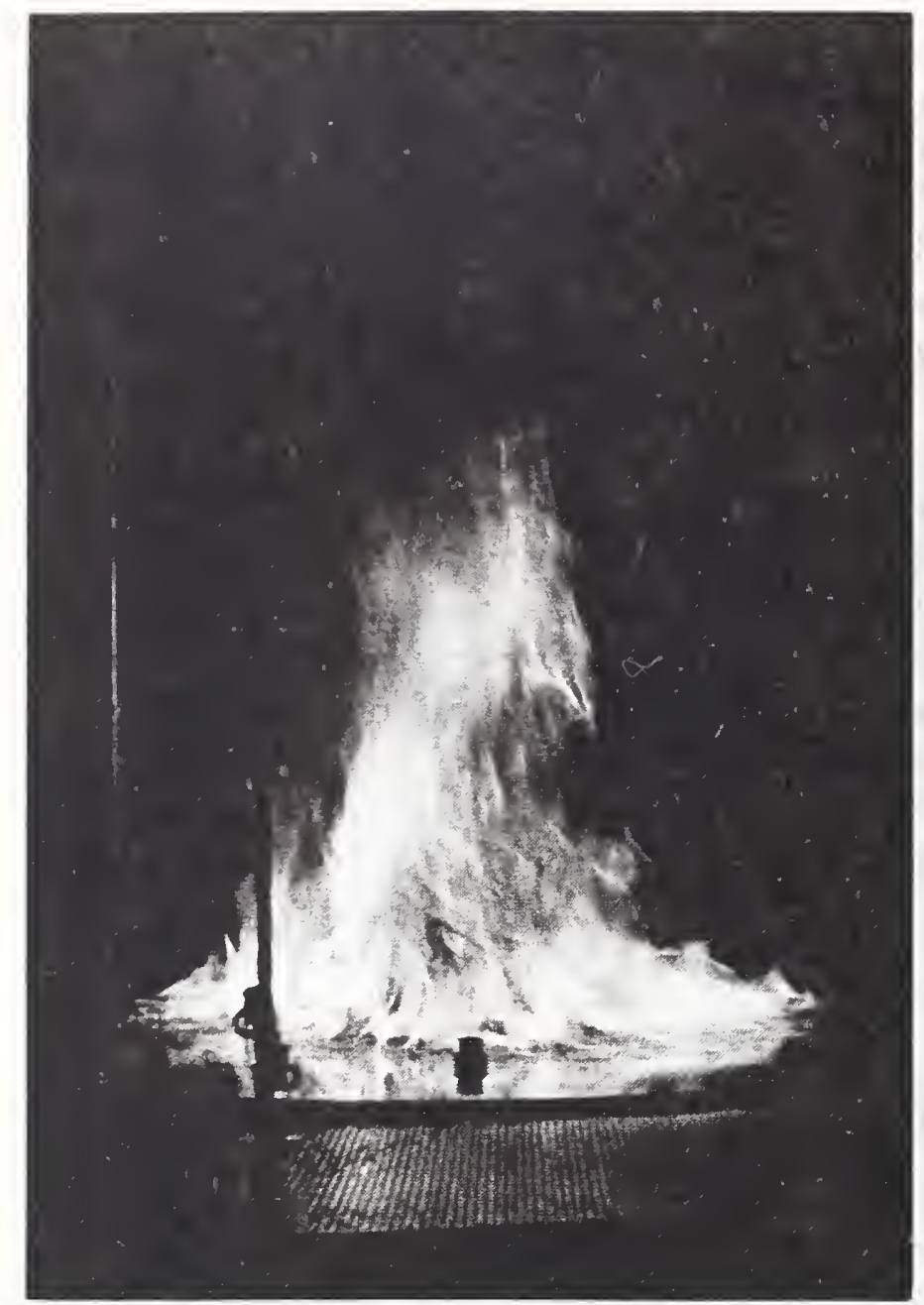

$T=1.0 \mathrm{MIN}$

FIRE GROWTH PERIOD

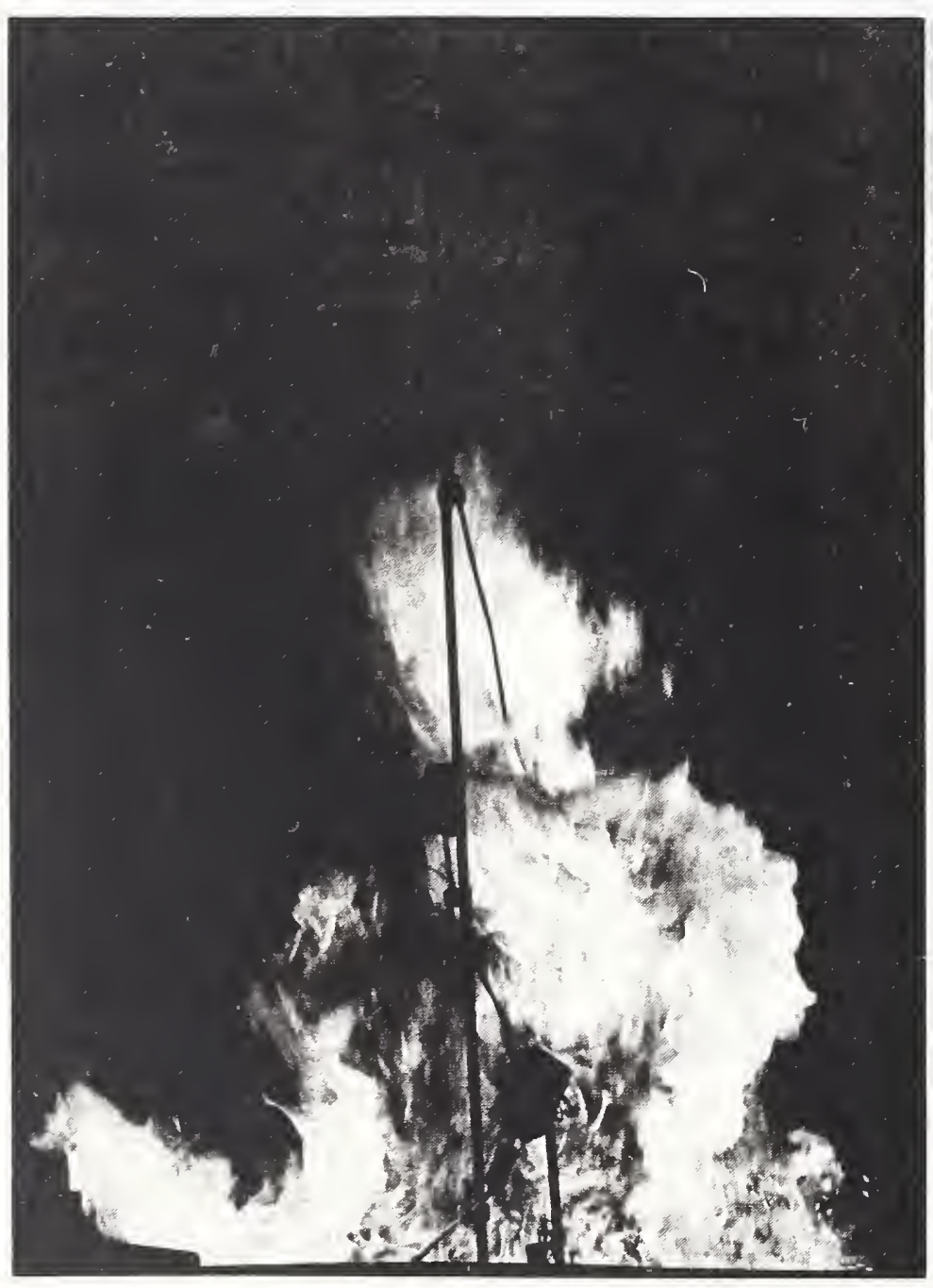

$\mathrm{T}=3.0 \mathrm{MIN}$.

NEAR END OF STEADY-STATE BURNING PERIOD

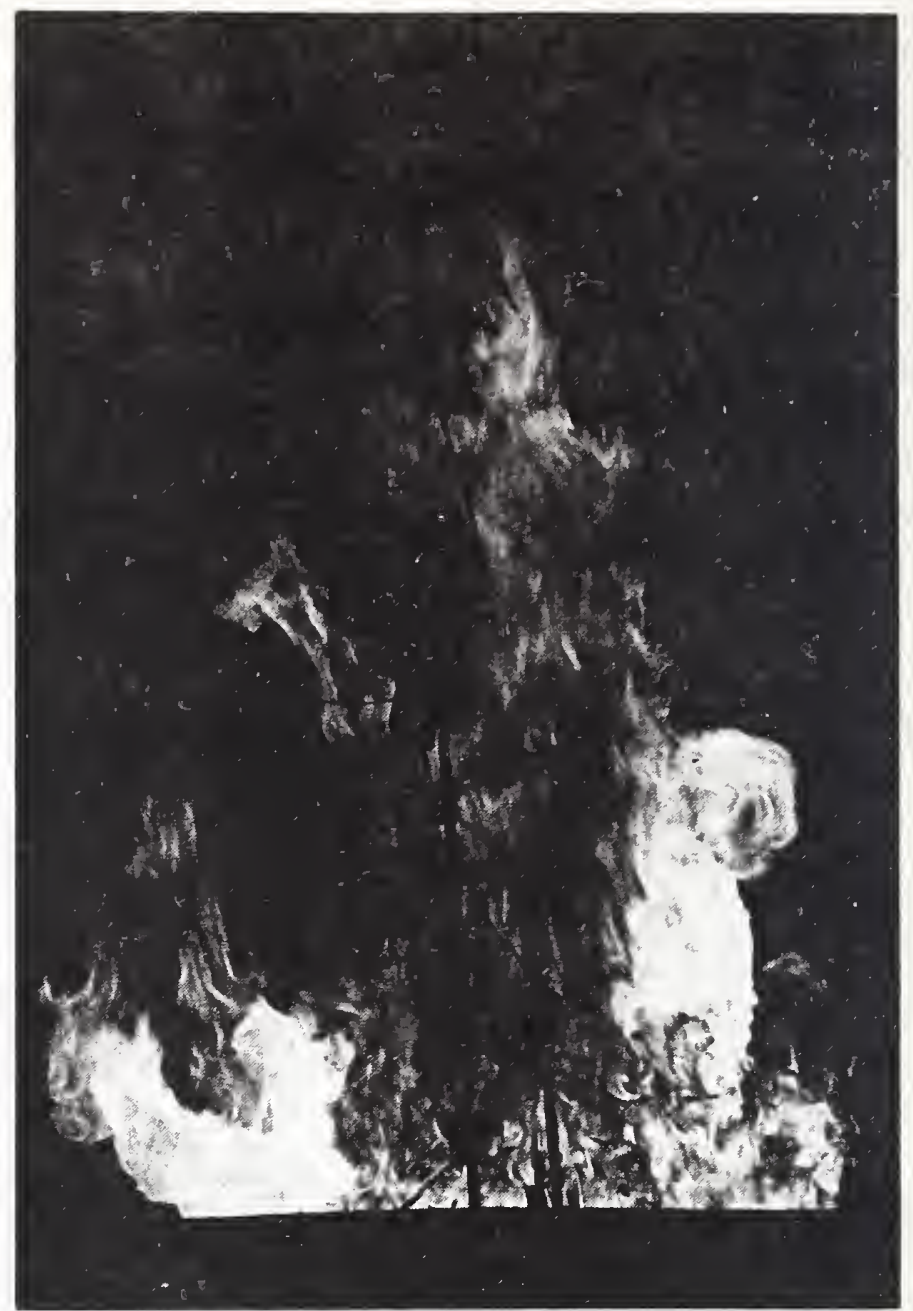

$\mathrm{T}=2.0 \mathrm{MIN}$

START OF STEADY-STATE BURNING PERIOD

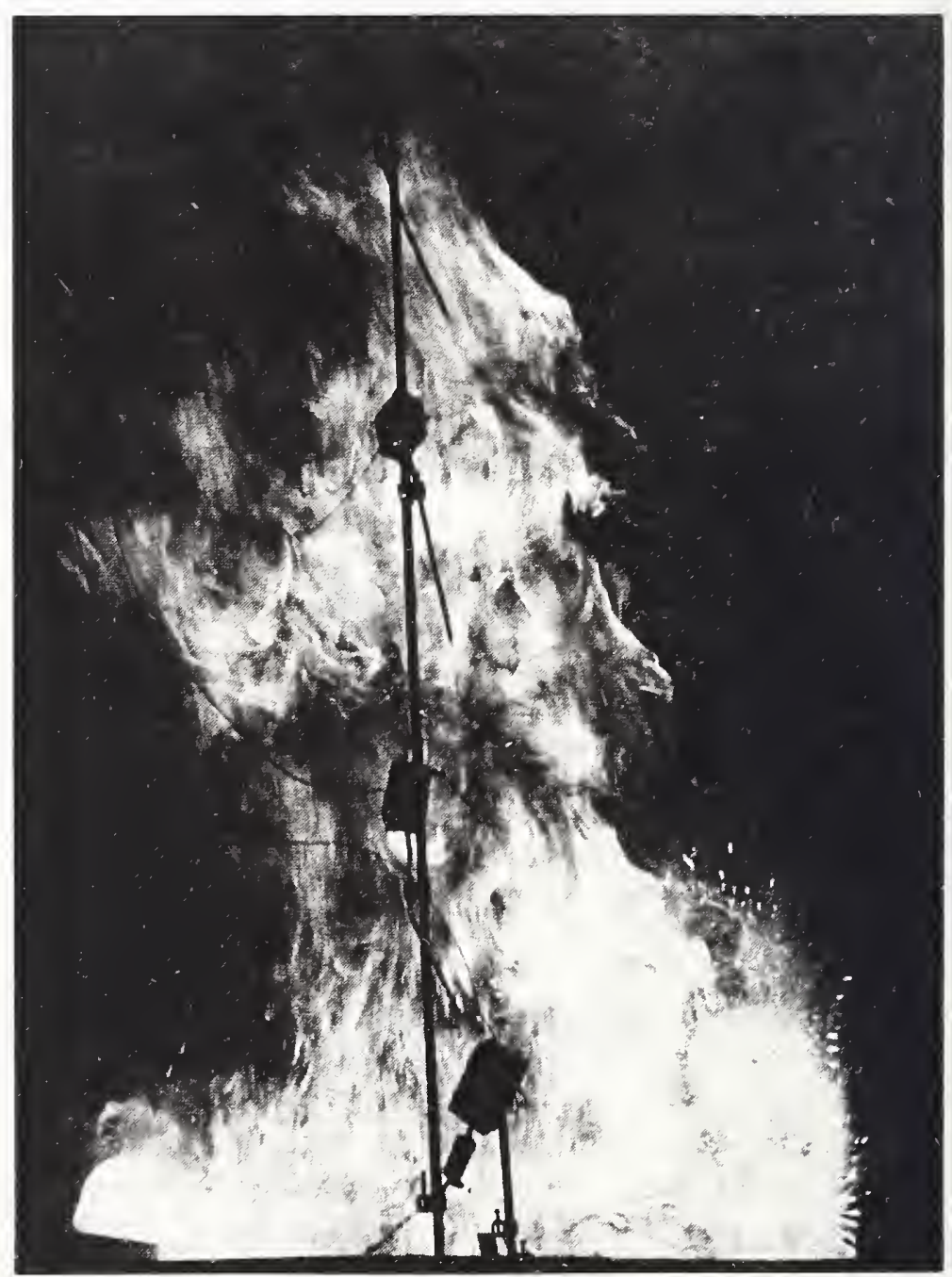

$\mathrm{T}=4.0 \mathrm{MIN}$.

VIGOROUS BURNING PERIOD

FIGURE 5. BURN SEQUENCE FOR 10 MM THICK LAYER OF LA ROSA CRUDE OIL 


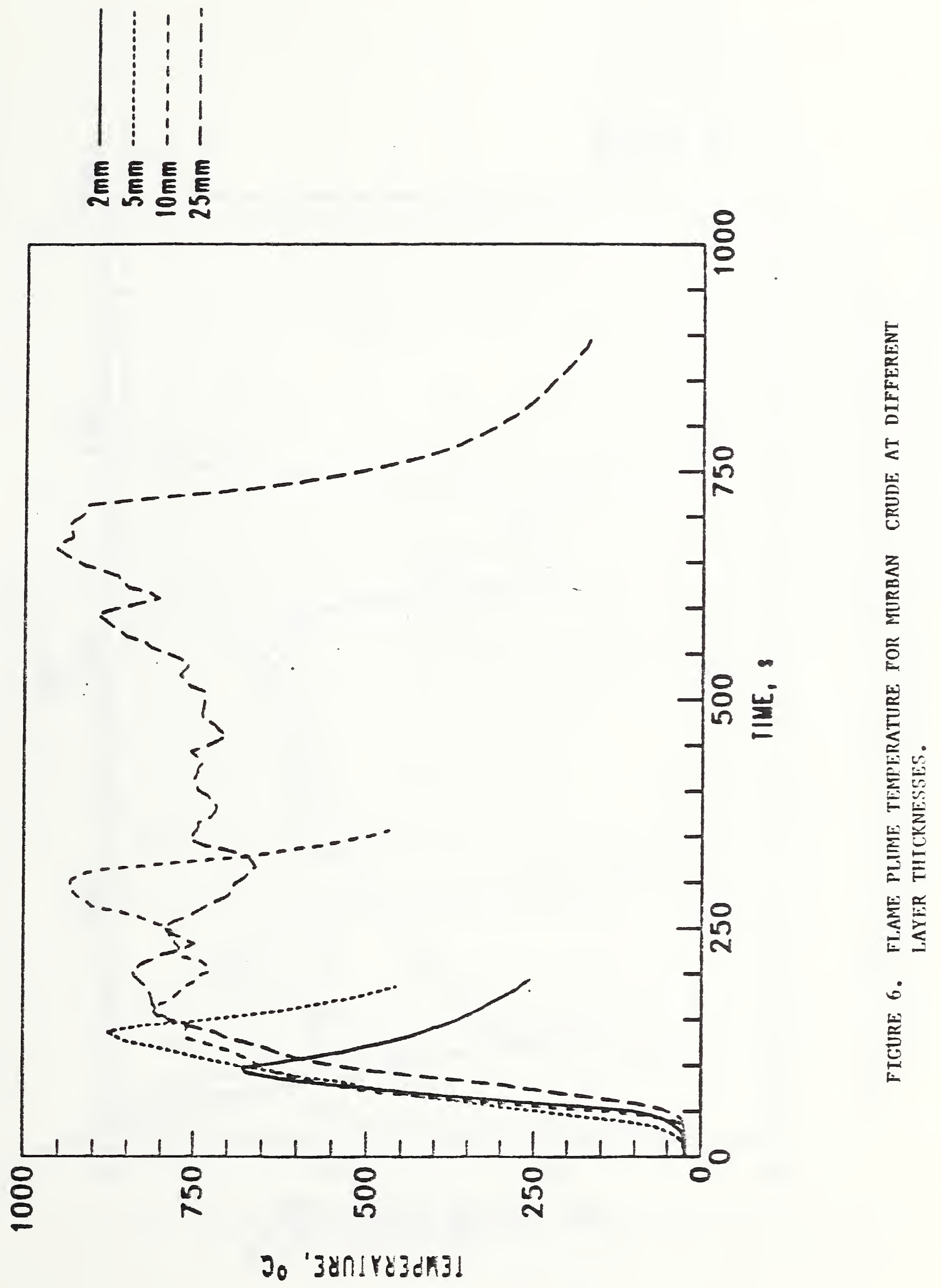




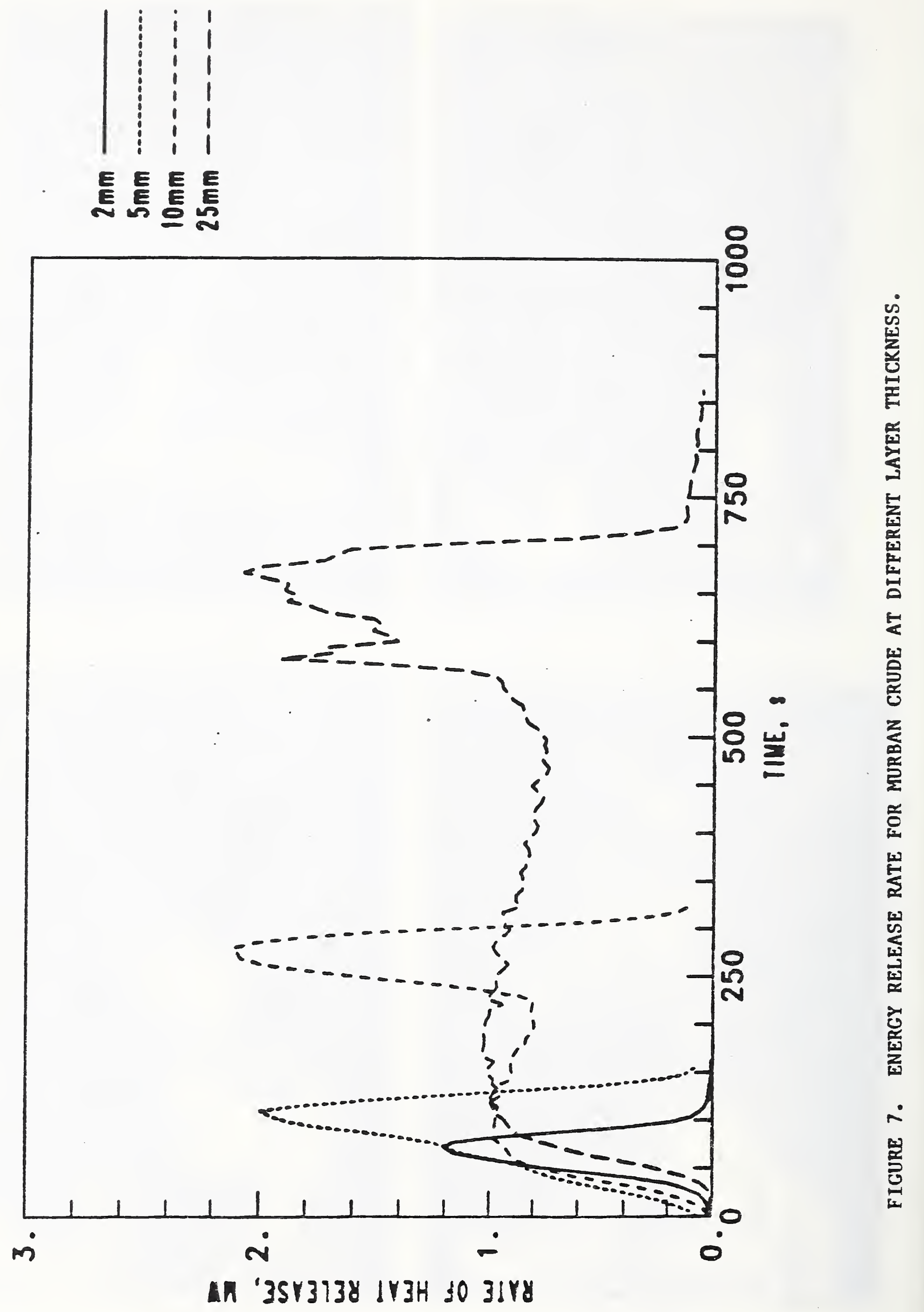




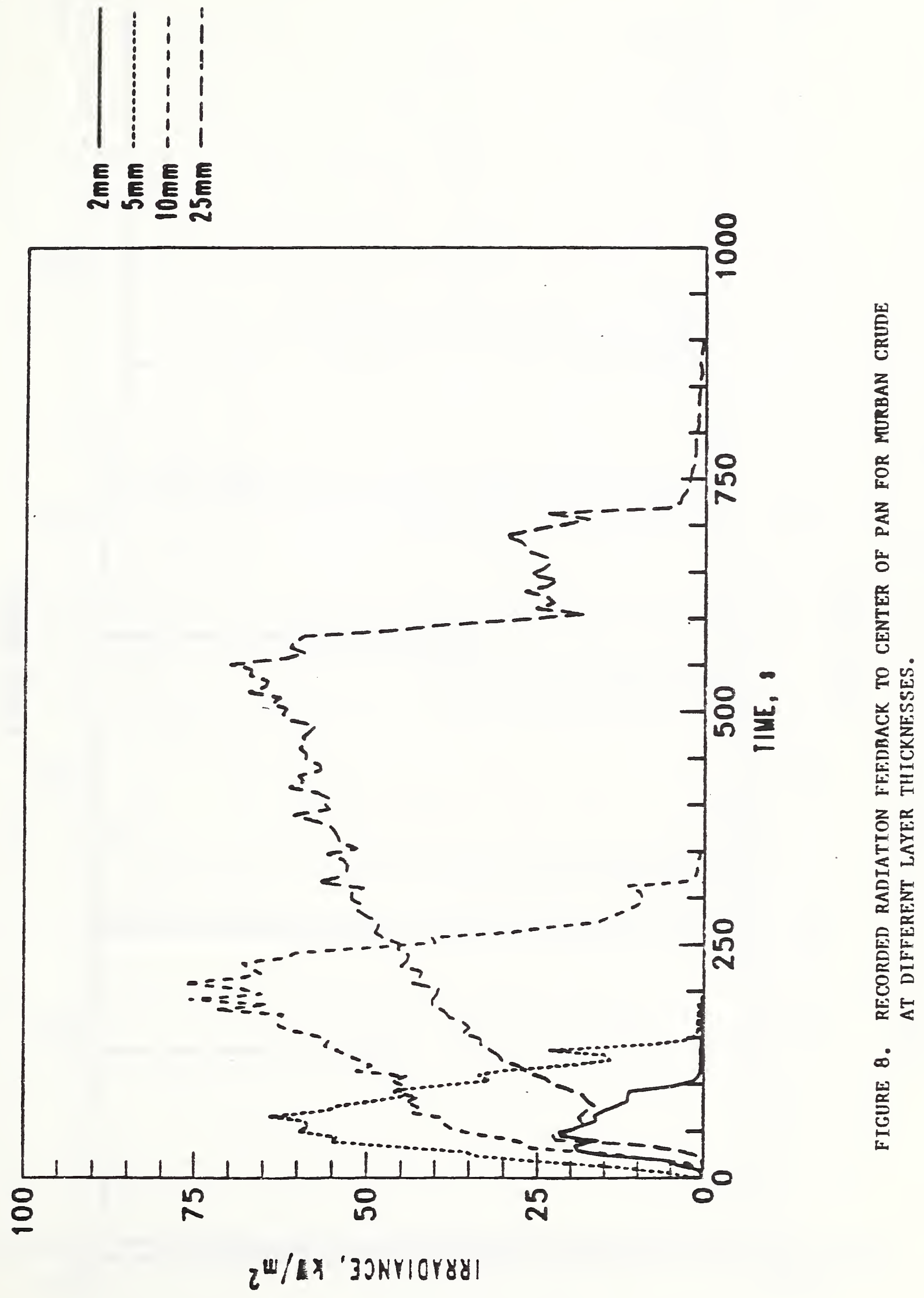




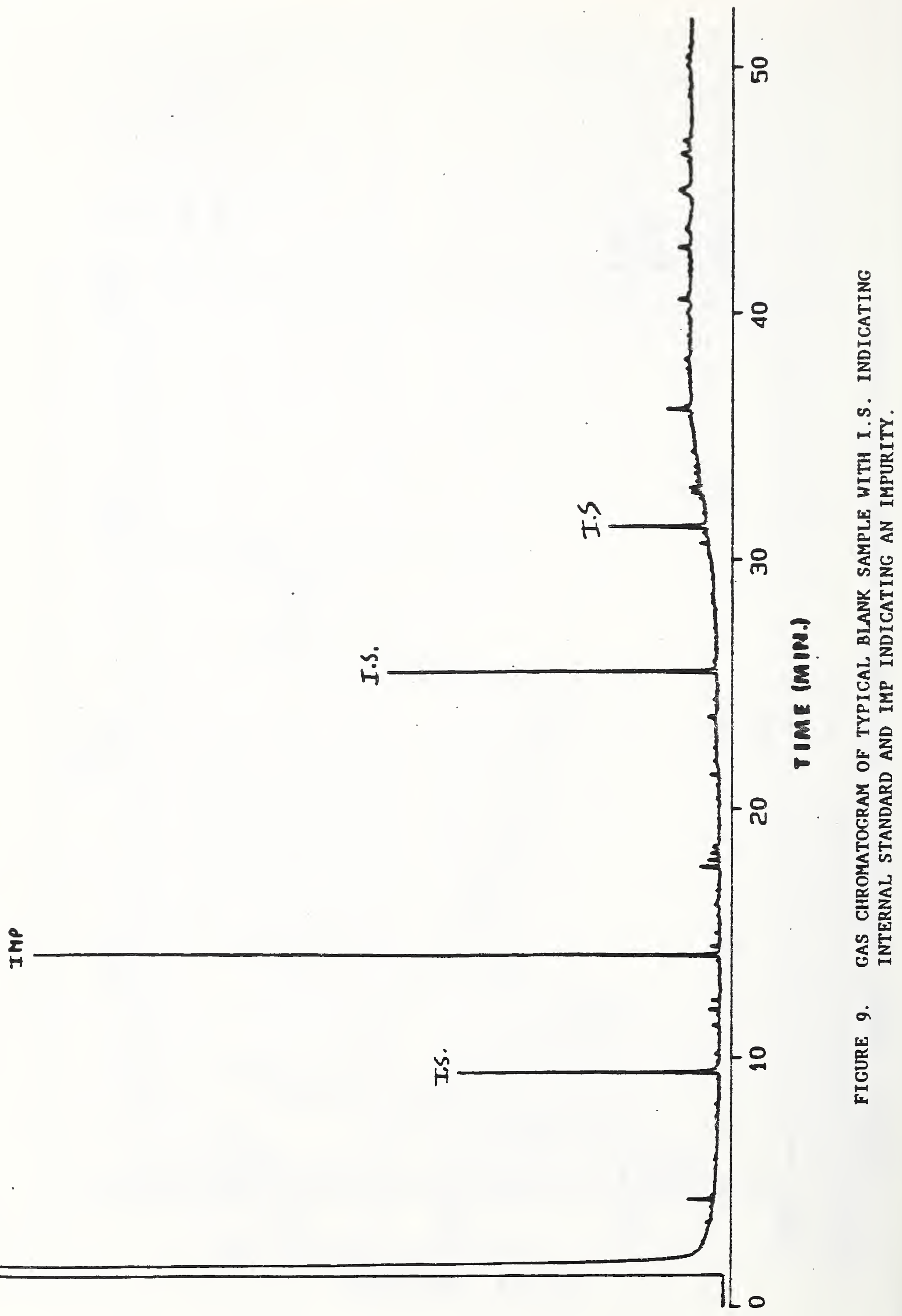




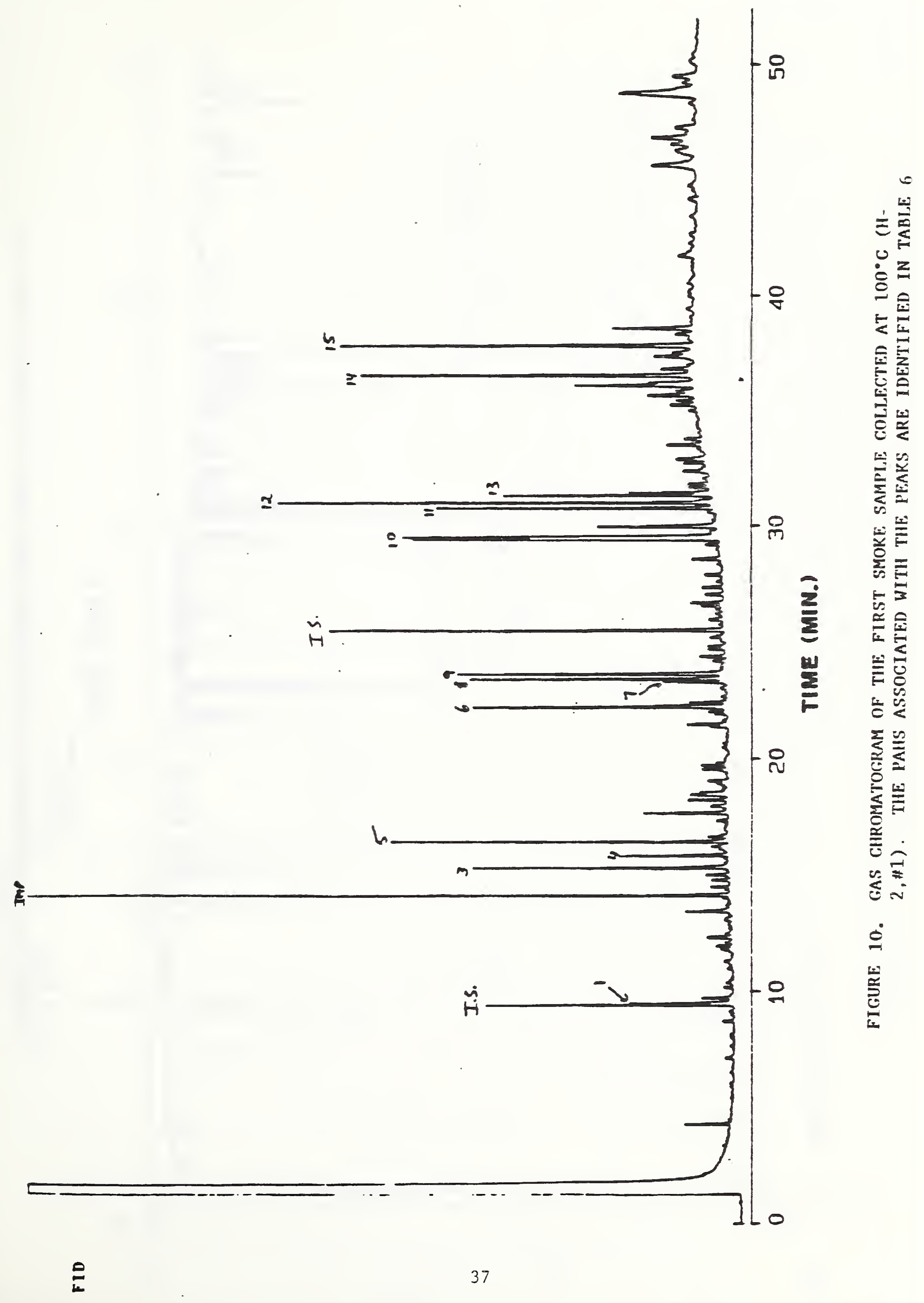




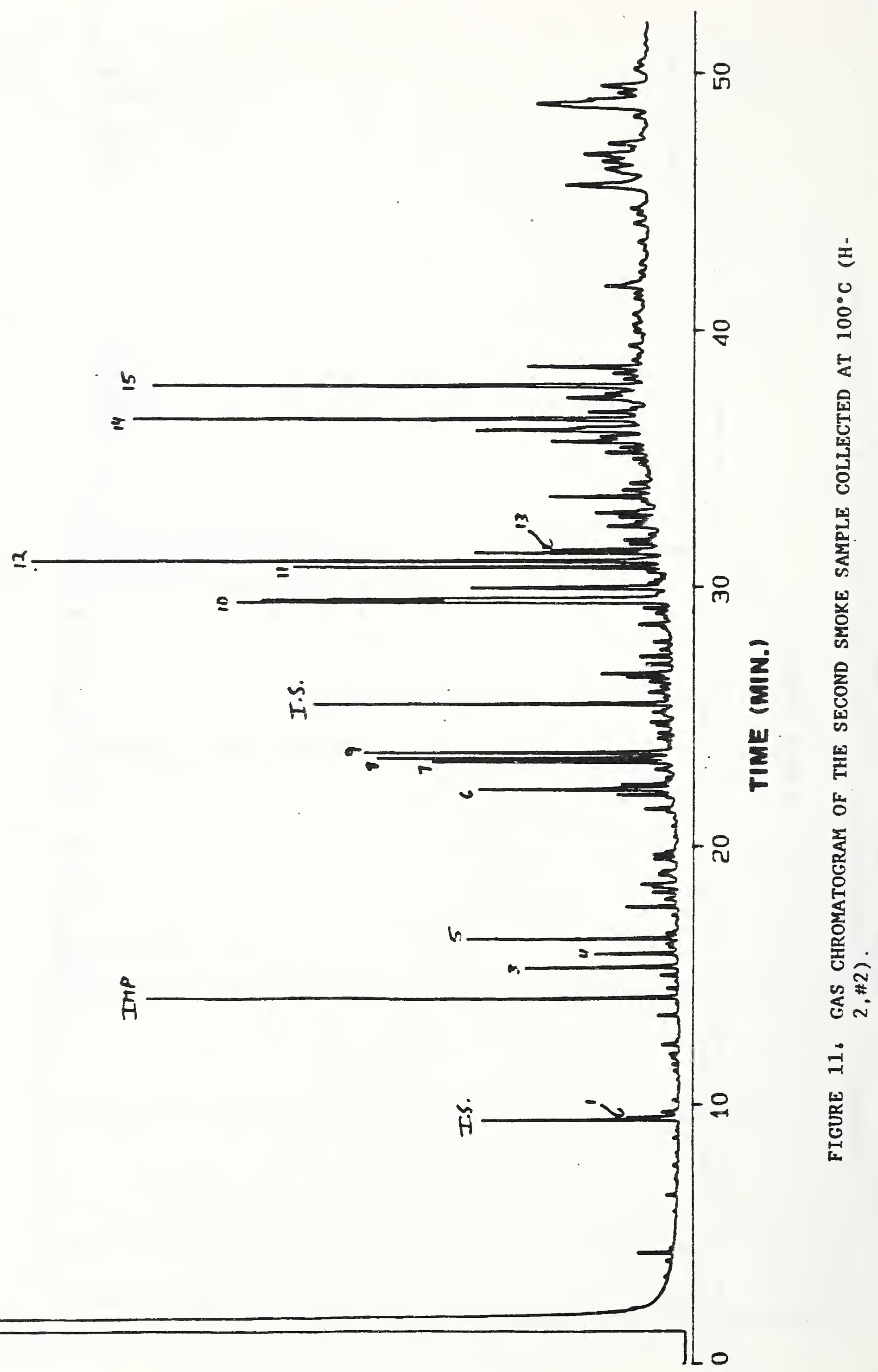

E 



$\underset{1}{2}$ 


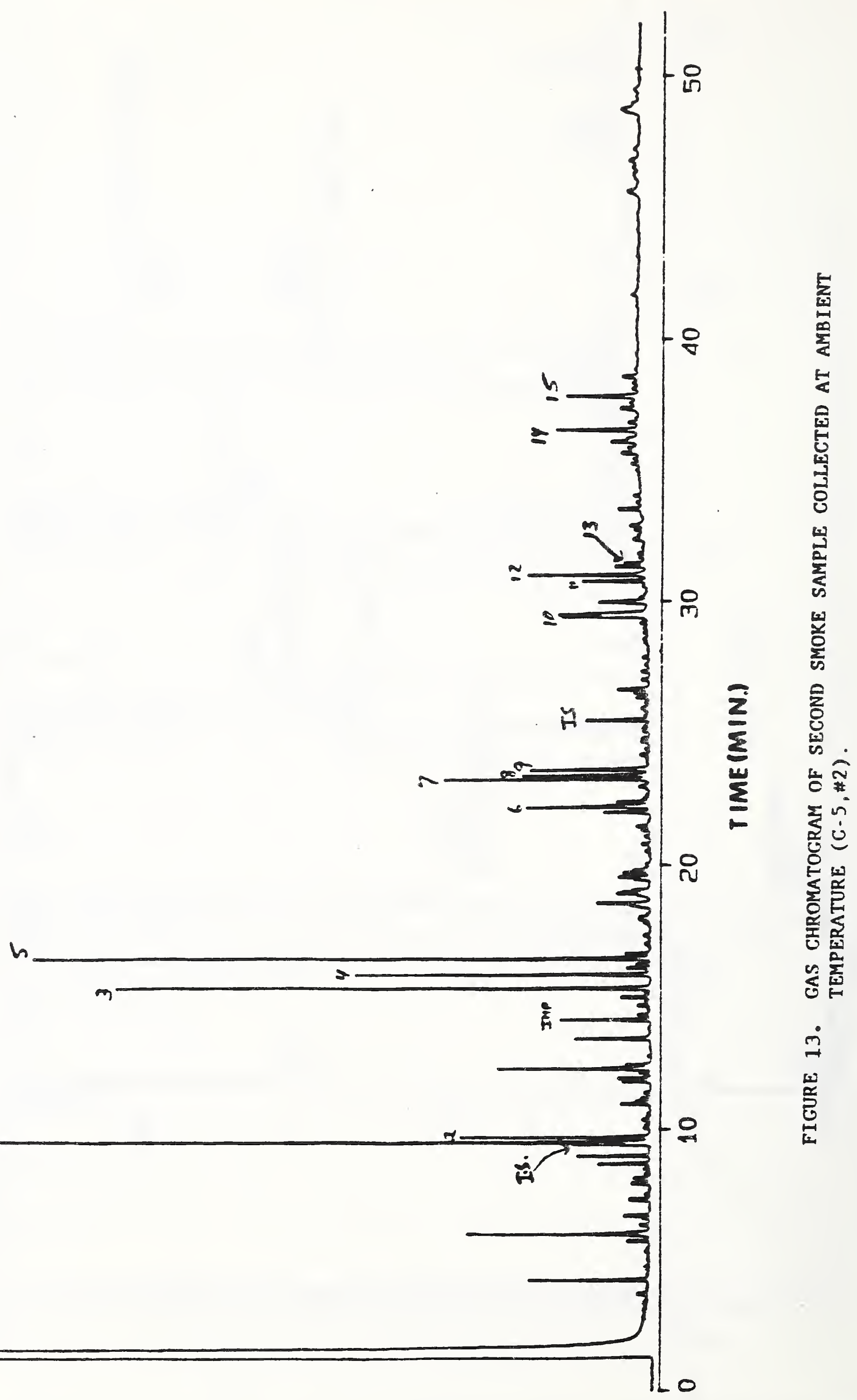




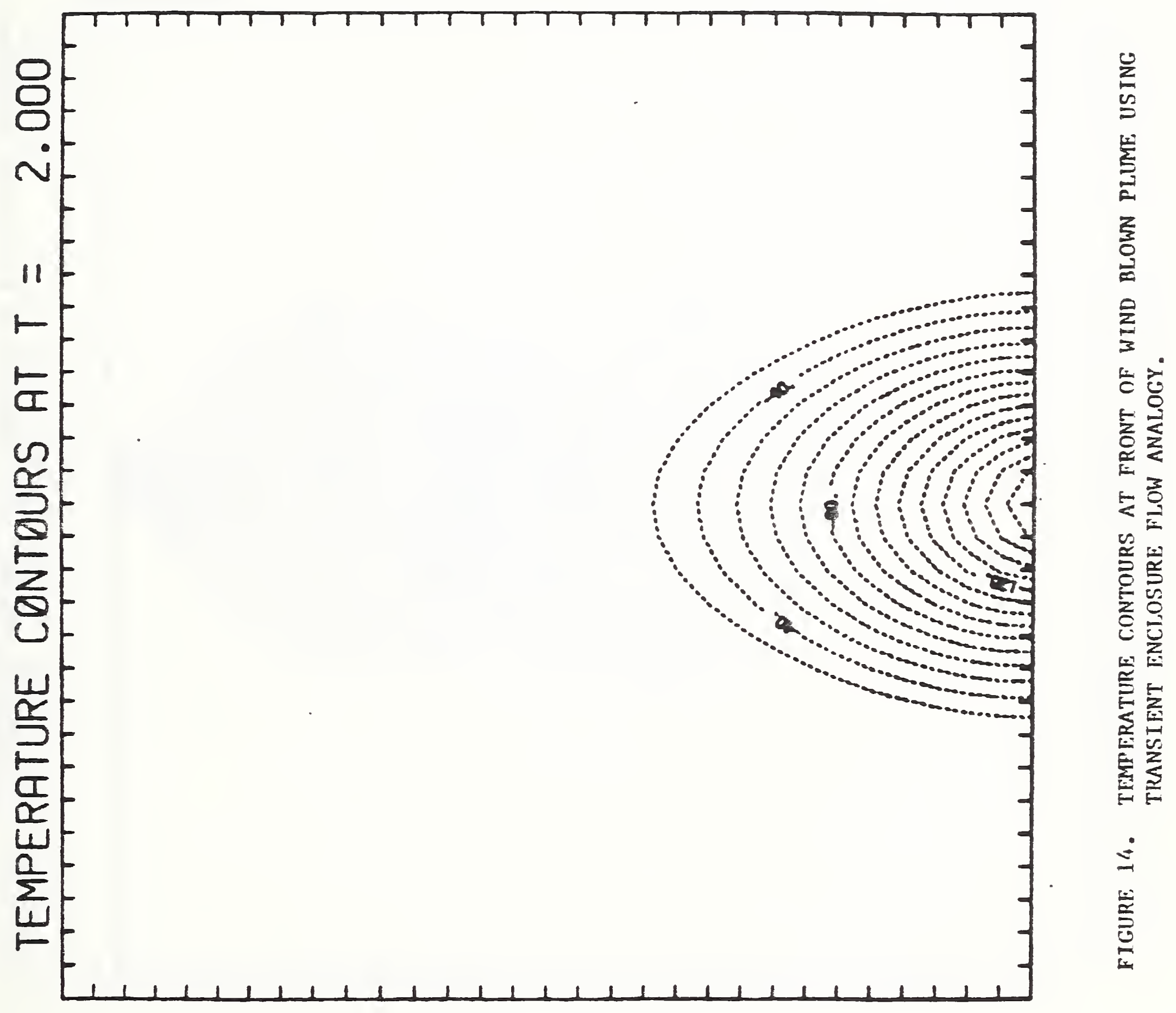




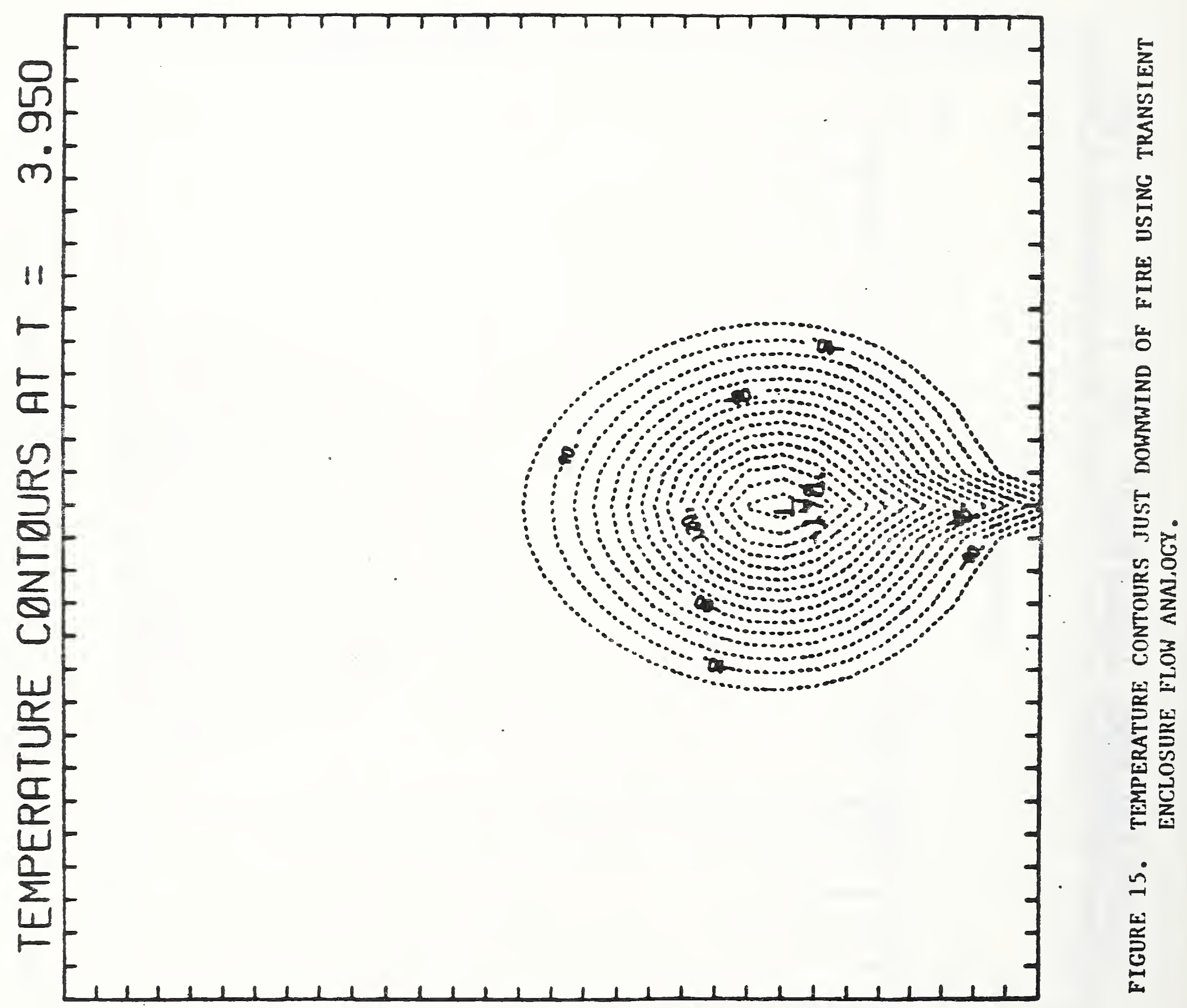




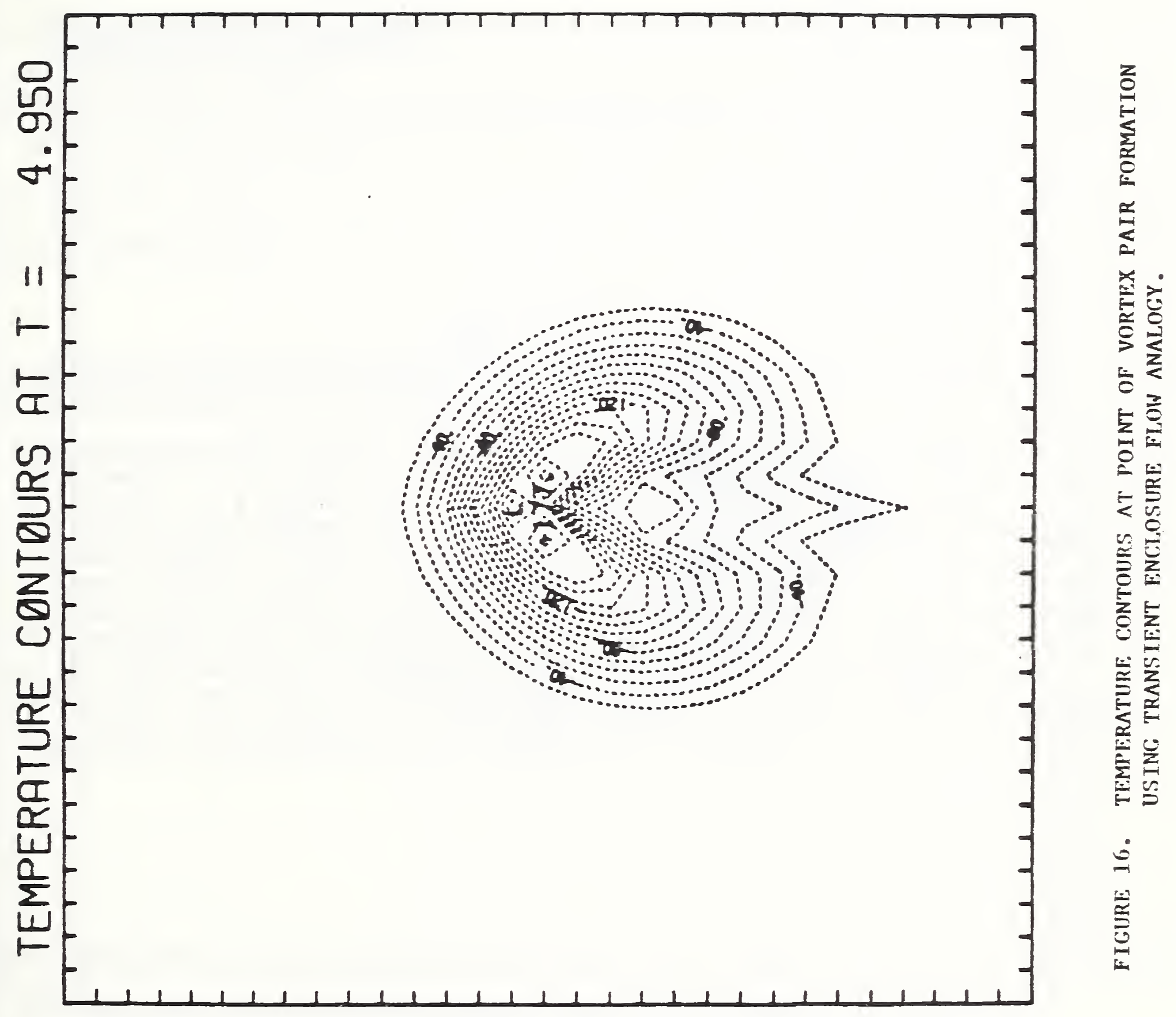




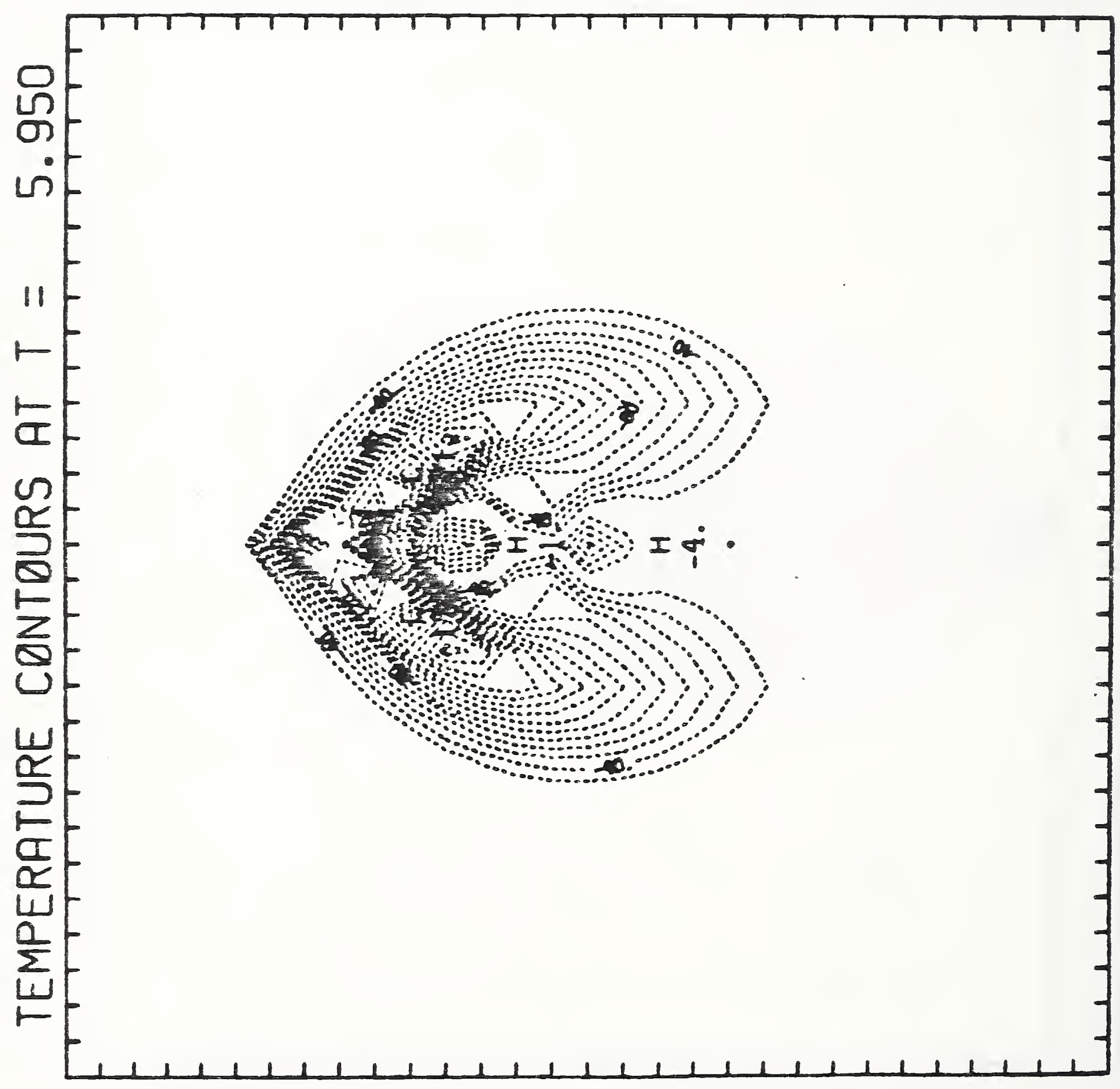

留 
4. TITLE AND SUBTITLE

Environmental Effects of 011 Spill Combustion

5. $\operatorname{AUTHOR}(S)$

D. Fuans G. Mulholland D. Gross and $H$. Baum

6. PERFORMING ORGANIZATION (If joint or other than NBS, see instructions)

7. Contracd Grant No.

\section{NATIONAL BUREAU OF STANDARDS \\ U.S. DEPARTMENT OF COMMERCE \\ GAITHERSBURG, MD 20899}

9. SPONSORING ORGANIZATION NAME AND COMPLETE ADDRESS (Street, City, Siote, ZIP)

Minerals Management Service

Department of the Interior

Reston, VA 22091

10. SUPPLEMENTARY NOTES

Document describes a computer program; SF-185, FIPS Software Summary, is attached.

11. ABSTRACT (A 200-word or less foctual summary of most significant information. If tocument includes a significant bibliogrophy or literoture survey. mention it here)

Experimentation and analysis have been performed to quantify the combustion of crude oil on water. The burning behavior of three crude oils -- ALBERTA SWEET, LA ROSE, and MURBAN, were studied using $1.2 \mathrm{~m}$ diameter pool burns. In smaller $0.6 \mathrm{~m}$ diameter pool fires using AIBERTA SWEET, combustion products were collected for extensive chemical analysis. This analysis showed that about ]0\% of the crude ofl was converted to smoke in the combustion process. The $\mathrm{CO}$ concentration was a factor of 25 lower than the primary gaseous product $\mathrm{CO}_{2}$, and the emission of $\mathrm{NO}$ and $\mathrm{NO}_{\mathrm{x}}$ were less than one thousandth the concentration of $\mathrm{CO}_{2}$. The $\mathrm{PAH}$ content of the smoke was enriched in the larger molecular welght species in comparison with the original fuel. A methodology was developed with which the down wind dispersal of smoke generated by one or more oil spill fires in close proximity may be predicted. Initial results that demonstrate the capability of the analysis are presented.

12. KEY WORDS (Six to twelve entries; alphabetical order; capitalize only proper names; and separate key words by semicolons) crude oil; ollspills; PAH; pool fires; smoke; flre plumes

13. AVAILABILITY

$x$ Unlimited

For Official Distribution. Do Not Release to NTIS

Order From Superintendent of Documents, U.S. Government Printing Office, Washington, D.C. 20402.

[ Order From National Technical Information Service (NTIS), Springfield, VA. 22161
14. NO. OF PRINTED PAGES

51

15. Price

$\$ 13.95$ 
